\title{
Phosphodiester modifications in mRNA poly(A) tail prevent deadenylation without compromising protein expression
}

\author{
DOMINIKA STRZELECKA, ${ }^{1,3}$ MIROSLAW SMIETANSKI, ${ }^{2,3}$ PAWEL J. SIKORSKI, ${ }^{2}$ MARCIN WARMINSKI, ${ }^{1}$ \\ JOANNA KOWALSKA, ${ }^{1}$ and JACEK JEMIELITY ${ }^{2}$ \\ ${ }^{1}$ Division of Biophysics, Institute of Experimental Physics, Faculty of Physics, University of Warsaw, 02-093 Warsaw, Poland \\ ${ }^{2}$ Centre of New Technologies, University of Warsaw, 02-097 Warsaw, Poland
}

\begin{abstract}
Chemical modifications enable preparation of mRNAs with augmented stability and translational activity. In this study, we explored how chemical modifications of $5^{\prime}, 3^{\prime}$-phosphodiester bonds in the mRNA body and poly(A) tail influence the biological properties of eukaryotic mRNA. To obtain modified and unmodified in vitro transcribed mRNAs, we used ATP and ATP analogs modified at the $\alpha$-phosphate (containing either O-to-S or O-to- $\mathrm{BH}_{3}$ substitutions) and three different RNA polymerases-SP6, T7, and poly(A) polymerase. To verify the efficiency of incorporation of ATP analogs in the presence of ATP, we developed a liquid chromatography-tandem mass spectrometry (LC-MS/MS) method for quantitative assessment of modification frequency based on exhaustive degradation of the transcripts to 5'-mononucleotides. The method also estimated the average poly(A) tail lengths, thereby providing a versatile tool for establishing a structure-biological property relationship for mRNA. We found that mRNAs containing phosphorothioate groups within the poly(A) tail were substantially less susceptible to degradation by $3^{\prime}$-deadenylase than unmodified mRNA and were efficiently expressed in cultured cells, which makes them useful research tools and potential candidates for future development of mRNA-based therapeutics.
\end{abstract}

Keywords: deadenylation; mRNA modification; resistance; transcription; translation

\section{INTRODUCTION}

In recent years, in vitro transcribed (IVT) mRNA has emerged as a promising candidate for therapeutic gene delivery (Sahin et al. 2014; Kariko 2019). Since proper mRNA function is dependent on its structural regulatory elements, a 5' cap, 5' and $3^{\prime}$ untranslated regions (UTRs), and the poly $(A)$ tail at the $3^{\prime}$ end, rational modifications of these elements improve the potency of mRNA therapeutics. The use of both natural and unnatural chemical modifications of mRNA have paved the way to modulating stability, translational properties, and immunogenicity of IVT mRNAs (Anderson et al. 2010; Jemielity et al. 2010; Kariko et al. 2012; Sahin et al. 2014). One of the structural elements that affect mRNA half-life and translation is the $5^{\prime}$ terminal 7-methylguanosine cap (Topisirovic et al. 2011). Modifications of the $5^{\prime}$ cap may lead to augmented mRNA stability and expression in living cells (GrudzienNogalska et al. 2007; Ziemniak et al. 2013; Kowalska

\footnotetext{
${ }^{3}$ These authors contributed equally to this work.

Corresponding authors: jkowalska@fuw.edu.pl, j.jemielity@ cent.uw.edu.pl

Article is online at http://www.rnajournal.org/cgi/doi/10.1261/rna. 077099.120. Freely available online through the RNA Open Access option.
}

et al. 2014; Walczak et al. 2017; Wojtczak et al. 2018). mRNA body modification via replacing uridine with pseudouridine or 1-methylpseudouridine has been found to enhance mRNA stability and translational properties, while decreasing immunogenicity (Kariko et al. 2008; Svitkin et al. 2017; Parr et al. 2020). Introduction of particular sequences, such as the 3' UTR of $\beta$-globin downstream from the open reading frame (ORF) provides similar effects (Holtkamp et al. 2006; Benteyn et al. 2013; Geisberg et al. 2014; von Niessen et al. 2019). Improvement of translational properties has also been observed for mRNAs fluorescently labeled at the $3^{\prime}$ end of the poly(A) tail (Westerich et al. 2020).

The poly(A) tail is the stretch of adenylate residues at the $3^{\prime}$ end of most of the mature mammalian mRNAs (except histone-encoding replication-dependent genes [Marzluff et al. 2008]). Poly(A) tails of mature mammalian mRNAs consist of several dozens to up to 250 adenosine residues (Eckmann et al. 2011; Lima et al. 2017) and form cytoplasmic ribonucleoprotein (RNP) complexes with poly(A)-binding proteins (PABPs) (Mangus et al. 2003). The interaction

(C) 2020 Strzelecka et al. This article, published in RNA, is available under a Creative Commons License (Attribution 4.0 International), as described at http://creativecommons.org/licenses/by/4.0/. 
is necessary for efficient translation and controls mRNA stability (Bernstein et al. 1989; Wiederhold and Passmore 2010; Goss and Kleiman 2013). The poly(A)-PABP RNP complex interacts with the elF4G scaffold protein stimulating the translation initiation process (Gallie 1991); thus, the presence of a poly $(A)$ tail is essential for efficient protein expression. Poly $(A)$ tails undergo gradual shortening (deadenylation) in an mRNA-specific manner (Decker and Parker 1993), which is a necessary step before committing transcripts to one of the bulk mRNA decay pathways (Chen and Shyu 2011; Wahle and Winkler 2013). Deadenylation is catalyzed by two major cytoplasmic deadenylase complexes, Pan2-Pan3, which initiates this process, and Ccr4-Not, acting at a later stage, finishing deadenylation prior to mRNA body decay (Decker and Parker 1993; Yamashita et al. 2005). Structural features of poly(A) tail recognition by the Pan2-Pan3 deadenylase have been described, and the role of PABPs, together with poly(A), in forming a specific binding scaffold for the Pan2-Pan3 heterotrimer has been revealed (Schafer et al. 2019). Other studies revealed the possibility of stabilizing mRNA molecules by preventing deadenylation, which has been achieved by modifying the very $3^{\prime}$ end of mRNA (Astrom et al. 1991; Anhauser et al. 2019). Herein, we envisaged that the chemical space for modifying mRNA and mRNA poly(A) tails was potentially much wider. We have previously found that modifying the triphosphate chain of the mRNA 5' cap, for example, by replacing one of the phosphate moieties with phosphorothioate or boranophosphate, has beneficial effects on mRNA stability and translation. However, modifications of phosphodiester bonds in the mRNA body or poly(A) tails have never been explored in this context. Here, we systematically investigated the effects of phosphodiester bonds modification on mRNA stability and translational properties to map out a detailed structure-activity relationship (SAR). To obtain phosphodiester-modified mRNAs (P-mod mRNAs), we utilized ATP analogs with nonbridging oxygen atom substitutions at the $\alpha$-phosphate, that is, ATP $\alpha S$ and $\mathrm{ATP} \alpha \mathrm{BH}_{3}$, which are enzymatically incorporated into RNA by means of RNA polymerases (Griffiths et al. 1987; Wan and Shaw 2005). However, this goal posed significant analytical challenges associated with the control and determination of $\operatorname{poly}(A)$ tail length and modification frequency. Thus, the development of proper analytical methods is a necessary prerequisite for further exploration of unnatural poly(A) tail modifications and precise determination of SAR in a manner previously achieved for the 5' cap.

Several methods to measure poly(A) tail lengths have been reported, including the polymerase-based poly(A) length assay engaging capillary electrophoresis (Patil et al. 2014), ligation-mediated poly(A) test (LM-PAT), and RNase H-based assay (Murray and Schoenberg 2008). However, such methods are suitable for poly(A) tails of lim- ited length due to poor resolution of the applied analytical methods, which is additionally complicated by poly(A) tail heterogeneity (Jalkanen et al. 2014). The highest resolution sequencing method, such as TAlL-seq (Chang et al. 2014), PAlso-seq (Subtelny et al. 2014; Liu et al. 2019), and FLAM-seq (Legnini et al. 2019), provide information on nucleotide sequence, poly(A) tail length, and the presence of adenine modifications. Mass spectrometry has been successfully used in the analysis of RNA, including mRNA, either by direct infusion analysis or combined with chromatographic techniques (Kowalak et al. 1993; Gong and McCullagh 2014; Rose et al. 2015; Wetzel and Limbach 2016; Studzinska et al. 2017; Beverly et al. 2018; Lobue et al. 2019; Calderisi et al. 2020). This powerful technique provides information on RNA structure and composition, including poly(A) tail length. Although, it is a high-resolution and sensitive method, the analysis of long mRNA may be difficult because of multiply charged states and associated spectra complexity (Muddiman et al. 1996).

In this study, to enable the analysis of P-mod mRNAs, we developed a new liquid chromatography-tandem mass spectrometry (LC-MS/MS) method that enabled simultaneous quantification of the number of modified phosphodiester bonds and estimation of the average poly(A) tail lengths in mRNA (Fig. 1). Subsequently, we applied this method to characterize IVT P-mod RNAs carrying either phosphorothioate or boranophosphate modifications synthesized by three different RNA polymerases. Finally, LCMS/MS characterized P-mod mRNAs were studied in vitro to evaluate their susceptibility to enzymatic deadenylation and in cultured cells to estimate the influence of phosphodiester modifications on protein expression. We obtained the first glimpse of the SAR of P-mod RNAs and identified modification patterns that were compatible with efficient protein expression.

\section{RESULTS}

\section{LC-MS/MS enabled determination of the phosphorothioate moiety content in RNA and estimation of an average poly(A) tail length}

To enable systematic investigation of the SAR of modified RNAs, we developed an LC-MS/MS method for quantitative assessment of the incorporation of phosphate-modified ATP analogs into transcripts by RNA polymerases (Fig. 1). If $A T P \alpha S$ was utilized by the polymerase as a substrate, a modified RNA (modRNA) with phosphorothioate bonds was produced (Supplemental Fig. S1). For polymerases that have been studied so far, only the $S_{p}$ isomer of ATP $\alpha$ S has been accepted as a substrate, and the reaction proceeds with inversion of the configuration at the phosphorus atom (Burgers and Eckstein 1978). To assess the efficiency of ATP $\alpha$ S incorporation, modRNA was 


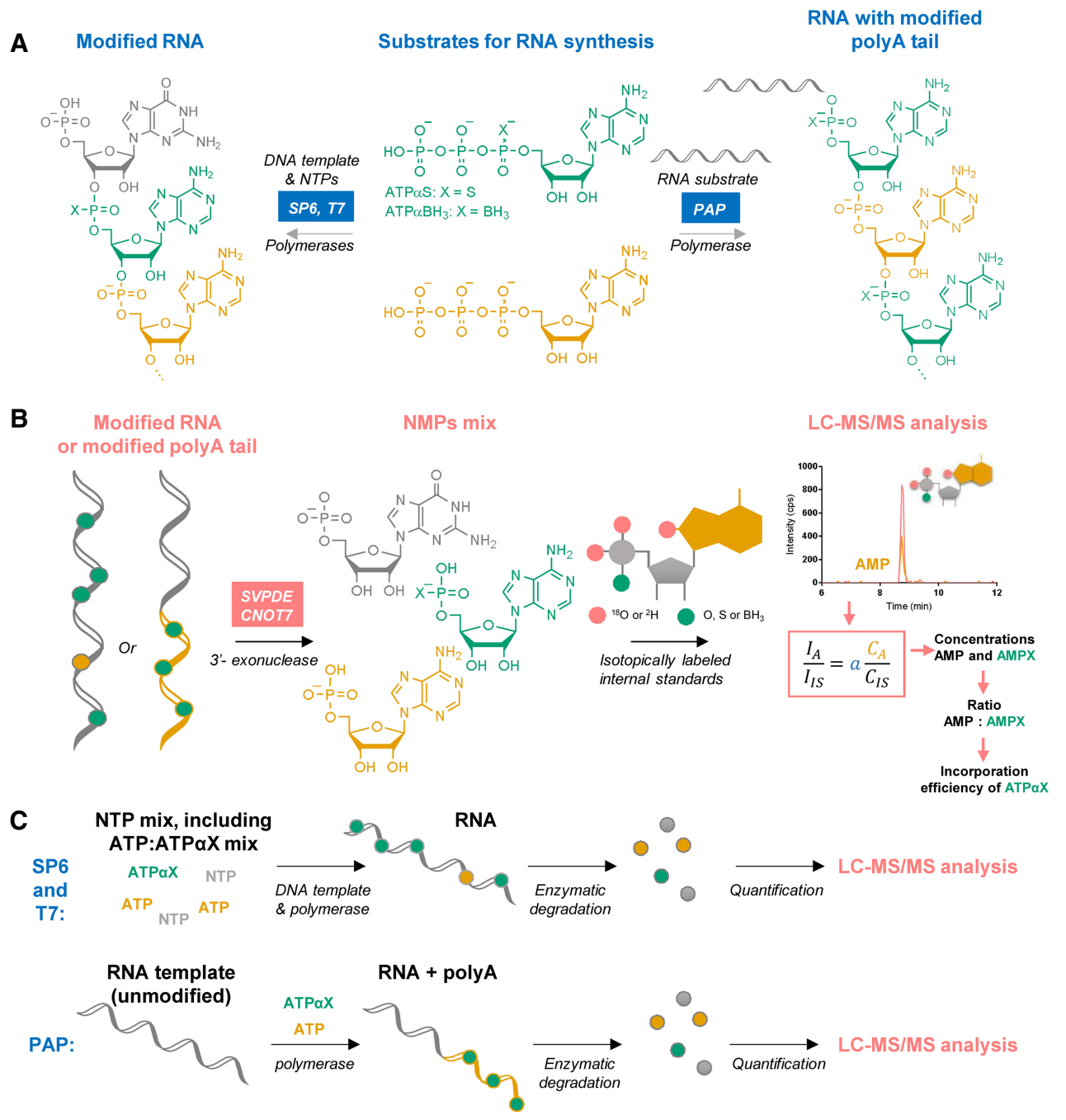

FIGURE 1. Synthesis and analysis of phosphate-modified RNA—experimental overview. (A) RNAs modified throughout the sequence are synthesized by in vitro transcription with the SP6 or T7 polymerase from a template also encoding the poly(A) tail in the presence of nucleoside triphosphates (NTPs) (left), whereas RNAs modified only within the poly(A) tail are synthesized by polyadenylation of unmodified RNA substrate with poly(A) polymerase (PAP) (right). (B) Modified RNAs are subjected to exhaustive degradation by a mix of nucleases and the resulting mononucleotides (adenosine monophosphate [AMP], modified AMP, and guanosine monophosphate [GMP] as a reference) are quantified using liquid chromatography-tandem mass spectrometry (LC-MS/MS) $\left(\left[I_{A}\right]\right.$ intensity of analyte, $\left[I_{I S}\right]$ intensity of internal standard, $\left[C_{A}\right]$ concentration of analyte, $\left[C_{I S}\right]$ concentration of internal standard, and [a] slope of calibration curve). (C) Simplified workflow from nucleotide incorporation to RNA degradation and analysis.

enzymatically degraded to single NMPs and adenosine $5^{\prime}$ phosphorothioate (AMPS). lon pair chromatography coupled with ESI and a triple quadrupole analyzer was then used to resolve and quantify AMPS and select NMPs. Synthetic isotopologs of RNA degradation products labeled with heavy oxygen $\left({ }^{18} \mathrm{O}\right)$ within the phosphate were used as internal standards to facilitate quantification. The data were then mathematically processed to determine the absolute concentrations of these nucleotides, the AMP/AMPS ratio, and, if an RNA of known sequence with a $3^{\prime}$ terminal poly(A) tract was analyzed, the average poly $(A)$ tail length was also estimated. We found that the key factor during method development was the optimiza- tion of the RNA degradation procedure to ensure complete RNA degradation to (modified) monophosphates, without further decomposition of released nucleotides.

To obtain isotopically labeled internal standards, chemical (thio)phosphorylation of nucleosides followed by hydrolysis with heavy water was applied (Supplemental Fig. S2; Strzelecka et al. 2017). Using this method, the internal standards containing two heavy oxygen $\left({ }^{18} \mathrm{O}\right)$ atoms in the phosphate group were synthesized for all tested NMPs and AMPS. Heavy AMPS, AMP, and GMP were used as internal standards for quantification of, respectively, AMPS, $A M P$, and GMP released during RNA degradation (Fig. 2A). Since guanine was present only in the main RNA 
A

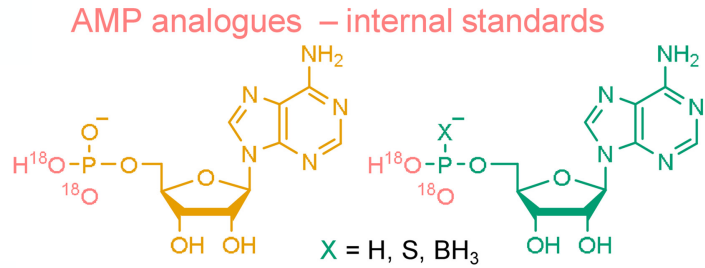

B

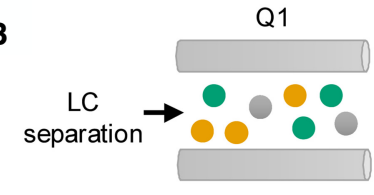

Parent ion $\left[\mathrm{M}-\mathrm{H}^{+}\right]^{-}$

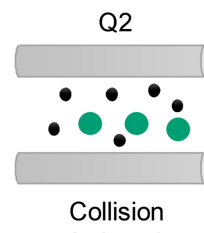

Induced

Dissociation
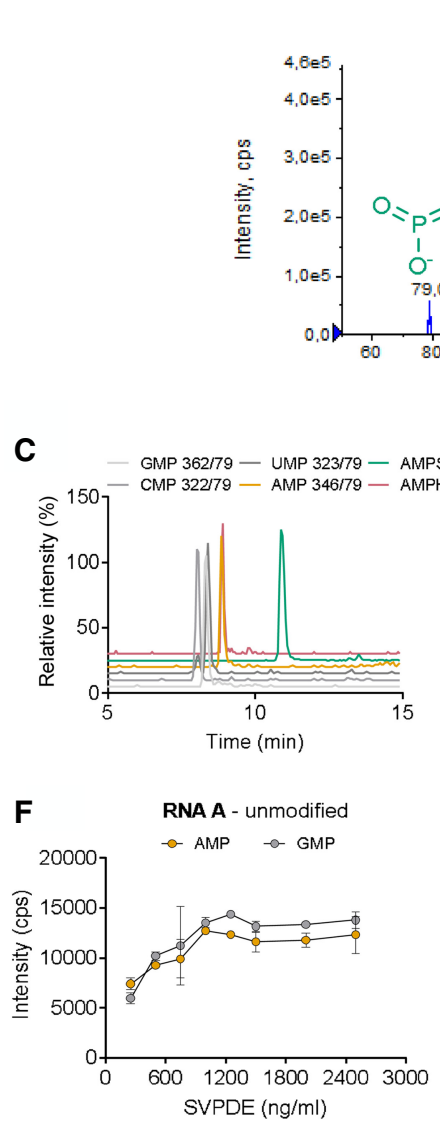

C

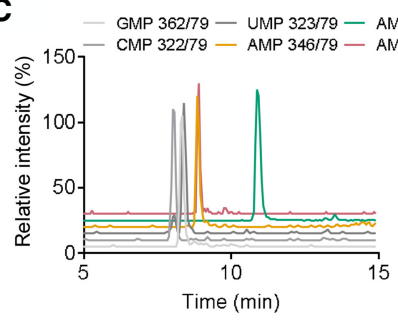

SVPDE (ng/ml)
GMP - internal standard of RNA

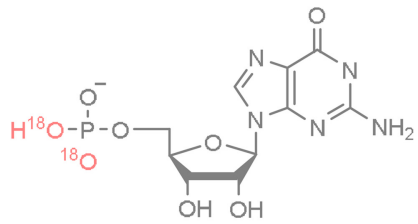

Q3

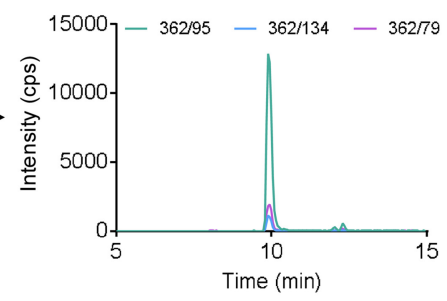

D
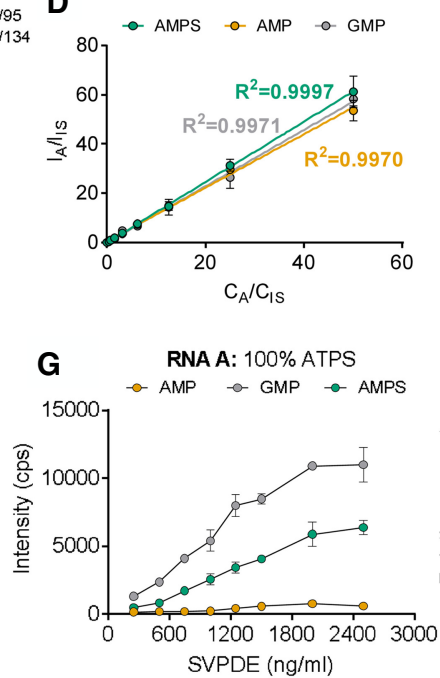

E RNA A: degradation products

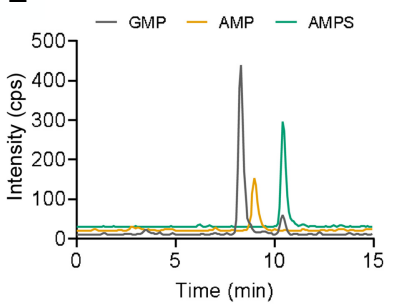

RNA A: $100 \%$ ATPS

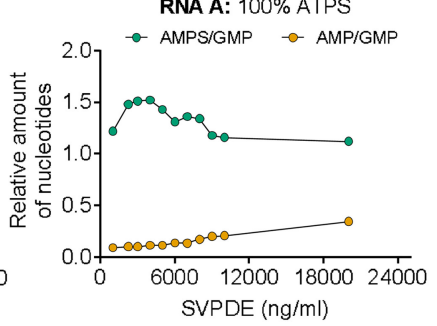

FIGURE 2. Liquid chromatography-tandem mass spectrometry (LC-MS/MS) method development. (A) Synthesis of isotopically labeled internal standards (heavy adenosine monophosphate [AMP], heavy adenosine 5'-O-monothiophosphate [AMPS], heavy guanosine monophosphate [GMP], heavy adenosine-5'-O-(H-phosphonate) [AMPH]); (B) identification and optimization of suitable multiple reaction monitoring (MRM) pairs; $(C)$ optimization of LC separation conditions; $(D)$ determination of calibration curves; $(E)$ high-performance liquid chromatography (HPLC)-MS analysis of an authentic RNA sample (phosphorothioate RNA A); and $(F, G)$ optimization of nuclease (snake venom phosphodiesterase [SVPDE]) concentrations to ensure complete degradation of RNA A (unmodified, F) or modified with phosphorothioate moieties (G).

body (and not the poly(A) tail), the quantity of GMP was used to normalize the amounts of RNAs that were analyzed, which was particularly important when comparing samples with different (or unknown) poly(A) tail lengths. The detection of AMPS and other NMPs was performed in MRM mode. MRM pairs were selected for each analyte and an internal standard based on the determined fragmentation pattern (Fig. 2B; Supplemental Table S1). The predominant fragmentation reaction for AMPS was the $362 \rightarrow 95$ transition, corresponding to the cleavage of 
the $5^{\prime}$-phosphorothioate bond and release of the $\mathrm{PSO}_{2}^{-}$ion (Strzelecka et al. 2017). The chromatographic conditions were also optimized to achieve good separation and a satisfactory peak shape for all studied analytes. To that end, ion pair chromatography with $\mathrm{N}, \mathrm{N}$-dimethylhexylamine $(\mathrm{DMH})$ as a mobile phase reagent (Auriola et al. 1997) has provided the best results in our hands (Fig. 2C). Calibration curves were subsequently determined for each analyte under optimized conditions (Fig. 2D; Supplemental Fig. S3). Based on the calibration curves, limits of quantification (LOQ) were determined (Supplemental Table S2). The final step of method development was establishing RNA degradation conditions. The goal was to achieve complete RNA degradation within a reasonable time, regardless of the modification content. This task was not trivial, since it has been known that the phosphorothioate modification, in general, stabilizes RNA against nucleolytic cleavage (Vortler and Eckstein 2000; Eckstein 2014). Moreover, we found that high concentrations of nucleolytic enzymes in the RNA sample leads to partial desulfurization of AMPS to AMP. Therefore, we tested different concentrations and mixtures of nucleolytic enzymes. We found that the optimal results were achieved for the mix of phosphodiesterase I Crotalus adamanteus venom (SVPDE) and human CNOT7 deadenylase. SVPDE, which is a commercially available $3^{\prime} \rightarrow 5^{\prime}$ exonuclease with broad spectrum specificity, releases $5^{\prime}$-mononucleotides (Williams et al. 1961); the enzyme is capable of degrading modified RNA (Stec and Zon 1984). The concentration of SVPDE in our assay was initially optimized using unmodified IVT RNA A and a fully modified RNA A. As expected, a higher enzyme concentration was required to completely degrade modified RNA A. However, during LC-MS/MS analysis of nucleotides released from fully modified RNA A, AMP was also found in the sample (Fig. 2E). This suggested that SVPDE at high concentrations also catalyzes AMPS desulfurization, which has been previously reported in the literature (Burgers and Eckstein 1978). Hence, we additionally optimized degradation by adjusting enzyme concentrations to maximize the AMPS to AMP ratio and maintain complete degradation of RNA (Fig. 2F,G). Next, we applied similar conditions to the degradation of longer RNAs, including mRNAs (RNA F2). We found that polyadenylated mRNAs were less susceptible to SVPDE compared to other RNAs. Therefore, to ensure complete degradation of polyadenylated RNAs, we used a mixture of SVPDE and CNOT7, which has $3^{\prime} \rightarrow 5^{\prime}$ poly(A) exoribonuclease activity (Bianchin et al. 2005). These conditions enabled complete degradation of most of the analyzed polyadenylated RNAs, while maintaining low desulfurization levels (Supplemental Fig. S4). To verify the extent of AMPS desulfurization under optimized digestion conditions, RNA E, which was devoid of an A in the sequence, was polyadenylated with a mixture of deuterated ATP ( $\left.{ }^{\mathrm{P} A T P}\right)$ and ATP $\alpha$ S D1, following RNA degradation and LC-MS/MS analysis.
The amount of undeuterated AMP, which could be derived only from AMPS, was 10\% (Supplemental Fig. S5). For each kind of RNA, the completeness of the digestion process was additionally verified by gel electrophoresis. If any undigested RNA was observed, the digestion conditions were adjusted individually, which was usually necessary for fully modified RNA.

For polyadenylated RNAs, the average poly(A) tail length was also estimated (Supplemental Fig. S6). To that end, the ratio of AMP and GMP concentrations $\left(r_{\text {ref }}\right)$ in the nonpolyadenylated RNA sequence was experimentally determined. Then, the average poly(A) tail length was calculated based on Equation 3. To initially verify the reliability of the method, we tested a chemically synthesized short RNA fragment (RNA C) containing a single G moiety and a string of adenosines (Supplemental Fig. S4A). The determined AMP to GMP ratio was comparable with the value expected based on the sequence.

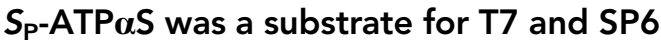 polymerases}

We next tested how efficiently the ATP analogs were incorporated into RNA during in vitro transcription and polyadenylation compared to unmodified ATP. Based on previously reported knowledge, we have assumed that $S_{P}-A T P \alpha S$ (isomer D1) will be incorporated into RNA, while $R_{\mathrm{P}}-\mathrm{ATP} \alpha \mathrm{S}$ (isomer D2) will be neither a substrate, nor an inhibitor (Lin et al. 2011). The in vitro transcription reactions were performed from a DNA template containing the promoter followed by a sequence of $35 \mathrm{nt}$ using a standard protocol for SP6 RNA polymerase or T7 RNA polymerase. The reactions contained different ratios of ATP to ATP $\alpha$ S (either D1 or D2 isomer). The yield and integrity of transcription products were analyzed by gel electrophoresis (Supplemental Fig. S1). High yields of IVT products were obtained in the presence of ATP $\alpha$ S D1 independently of the ATP:ATP $\alpha$ S D1 ratio used in the reaction with SP6 polymerase. In contrast, the presence of higher concentrations of ATP $\alpha$ S D2 isomer resulted in a lower transcription yield. The RNAs were then subjected to degradation by SVPDE and subjected to LC-MS/MS analysis (Fig. 3; Supplemental Fig. S7). The determined concentrations of AMP, AMPS, and GMP were plotted as a function of ATP $\alpha$ S D1 or D2 used in the in vitro transcription reaction (Supplemental Fig. S7A,B) and the data were normalized to GMP (Supplemental Fig. S7C,D). The AMPS to AMP ratio corresponded to the ATP $\alpha$ S D1 to ATP ratio (Supplemental Fig. S7A), indicating that ATP $\alpha$ S D1 incorporation efficiency was similar to that of ATP (Fig. 3A). In contrast, regardless of the ATP $\alpha$ S D2 to ATP ratio, AMPS was barely detected in RNA degradation products (Supplemental Fig. S7B). These findings are in good agreement with previous reports on the stereoselectivity of T7 RNA polymerase, which revealed that only isomer D1 is incorporated 


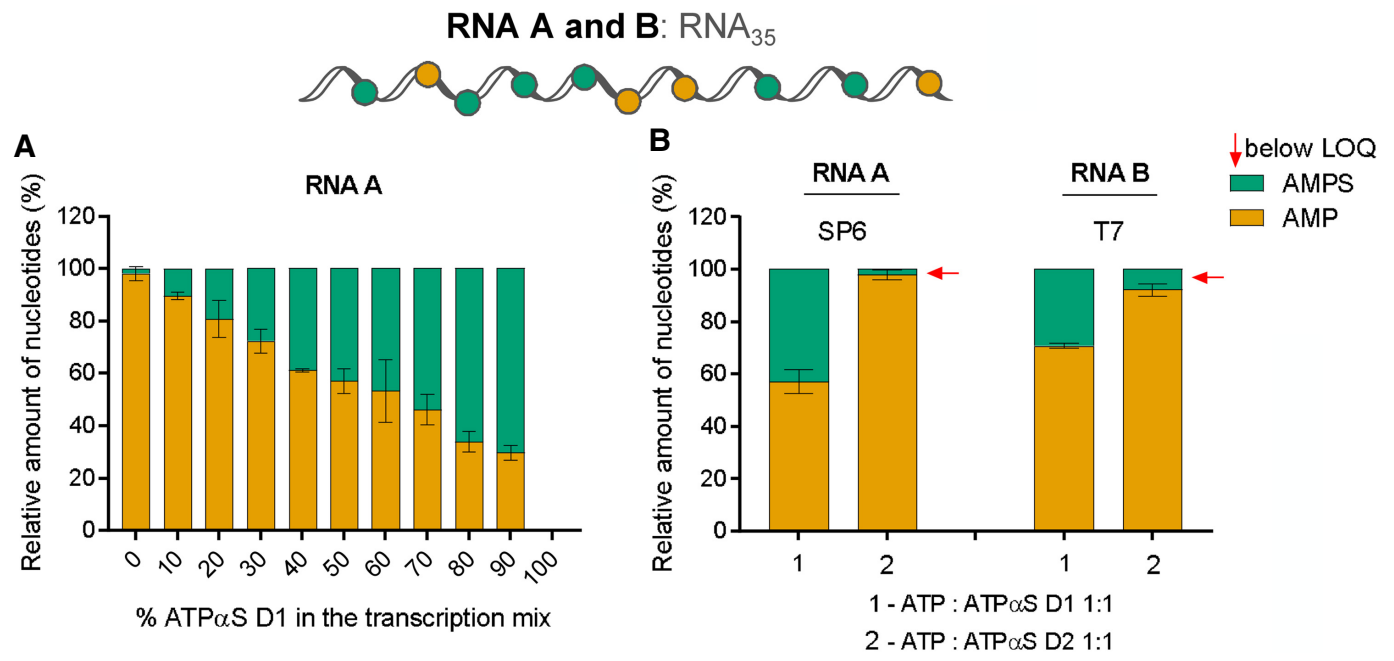

FIGURE 3. SP6 and T7 polymerases accept ATP $\alpha$ SD1 as a substrate. Short RNAs (RNAA or B) were obtained by in vitro transcription by SP6 or T7 RNA polymerase, respectively, in the presence of different ATP:ATP $\alpha$ S D1/D2 ratios. In vitro transcribed (IVT) RNAs (20 ng) were incubated with $3 \mu \mathrm{g} / \mathrm{mL}$ snake venom phosphodiesterase (SVPDE) for $1 \mathrm{~h}$ at $37^{\circ} \mathrm{C}$ (see Materials and Methods for further details). Concentrations of nucleotides after RNA digestion are determined based on liquid chromatography-tandem mass spectrometry (LC-MS/MS) analysis (Supplemental Fig. S7). The phosphorothioate moiety frequency in adenine nucleotides as a function of ATP $\alpha$ S D1 concentration in the transcription mix is shown in $A ; B$ shows the frequency of phosphorothioate moieties in adenine nucleotides found in RNAs obtained with SP6 and T7, and ATP $\alpha$ (either D1 or D2). Data represent mean values from triplicate experiments \pm standard deviation (SD).

(Griffiths et al. 1987; Lin et al. 2011). Next, we compared SP6 and T7 polymerase activities. To that end, the corresponding enzymatic reactions were performed by SP6 and T7 RNA polymerases in the presence of a 1:1 ATP: ATP $\alpha$ S ratio (Fig. 3B). We found that under the same conditions, T7 polymerase incorporated ATP $\alpha$ S D1 at a slightly lower frequency than SP6, whereas ATP $\alpha$ S D2 was not incorporated.

\section{High concentrations of ATPaS D1 in the transcription mix reduced the transcription yield and did not augment mRNA translational properties}

After establishing that both SP6 and T7 RNA polymerases incorporated ATP $\alpha$ S D1 into RNA, we determined how this phosphorothioate modification influenced the biological properties of mRNAs. This issue has rarely been investigated in the literature and, to the best of our knowledge, only in the context of prokaryotic mRNA (Ueda et al. 1991; Kawaguchi et al. 2020).

To this end, modified mRNAs encoding Firefly luciferase as a reporter gene (RNA F) were prepared by in vitro transcription. The template for the in vitro transcription reaction encoded a short $5^{\prime}$ UTR sequence, followed by the Firefly luciferase ORF, two consecutive $H$. sapiens $\beta$-globin $3^{\prime}$ UTRs, and a 128-nt long $\left(A_{128}\right)$ poly $(A)$ tail (Fig. 4A). Considering the determined stereoselectivity of $\mathrm{T7}$ and SP6 RNA polymerases (Fig. 3), we used the ATP $\alpha$ S D1 stereoisomer as a substrate for RNA modification. The typical in vitro transcription reaction contained a mix of unmodified NTPs (0.5 mM CTP, UTP, 0.125 mM GTP, and 1.25
$\mathrm{mM}$ cap analog $\beta$-S-ARCA), and a mix of ATP and ATP $\alpha$ S $\mathrm{D} 1$, at a total concentration of $0.5 \mathrm{mM}$ and varying molar ratios (10:0, 9:1, 2:1, 1:1, 1:4, or 0:10). To compare the transcription yields and quality of products, the transcripts were purified on a silica membrane and analyzed on an agarose gel (Fig. 4B). The transcription yield decreased with an increasing concentration of ATP $\alpha$ S D1 in the in vitro transcription mix. This suggested that ATP $\alpha$ S D1 was either a less efficient substrate of T7 and SP6 RNA polymerases or inhibited the activity of these RNA polymerases at higher concentrations.

RNA variants with different amounts of phosphorothioate modifications were then evaluated for their translation efficiency in the rabbit reticulocyte lysate (RRL). The lysate, optimized for cap-dependent translation, was programmed with RNA F and the amount of luciferase was determined after $60 \mathrm{~min}$ by luminometry. The translation efficiencies of RNA F decreased with an increasing concentration of ATP $\alpha$ S D1 used in the transcription mix (Fig. 4C). RNAs obtained in the presence of solely ATP $\alpha$ S D1 (i.e., in the absence of ATP) were translated at 10-fold lower efficiency than unmodified transcripts.

Overall, these results indicated that randomly modifying the entire mRNA sequence with phosphorothioate moieties reduced both the transcription yield and translational activity of mRNA. We envisaged that the most likely interferences with the translation processes resulted from the modifications within the ORF or UTRs, which may impair ribosomal movement. Thus, in the next steps of the study, we investigated properties of mRNAs modified solely within the poly(A) tails. 

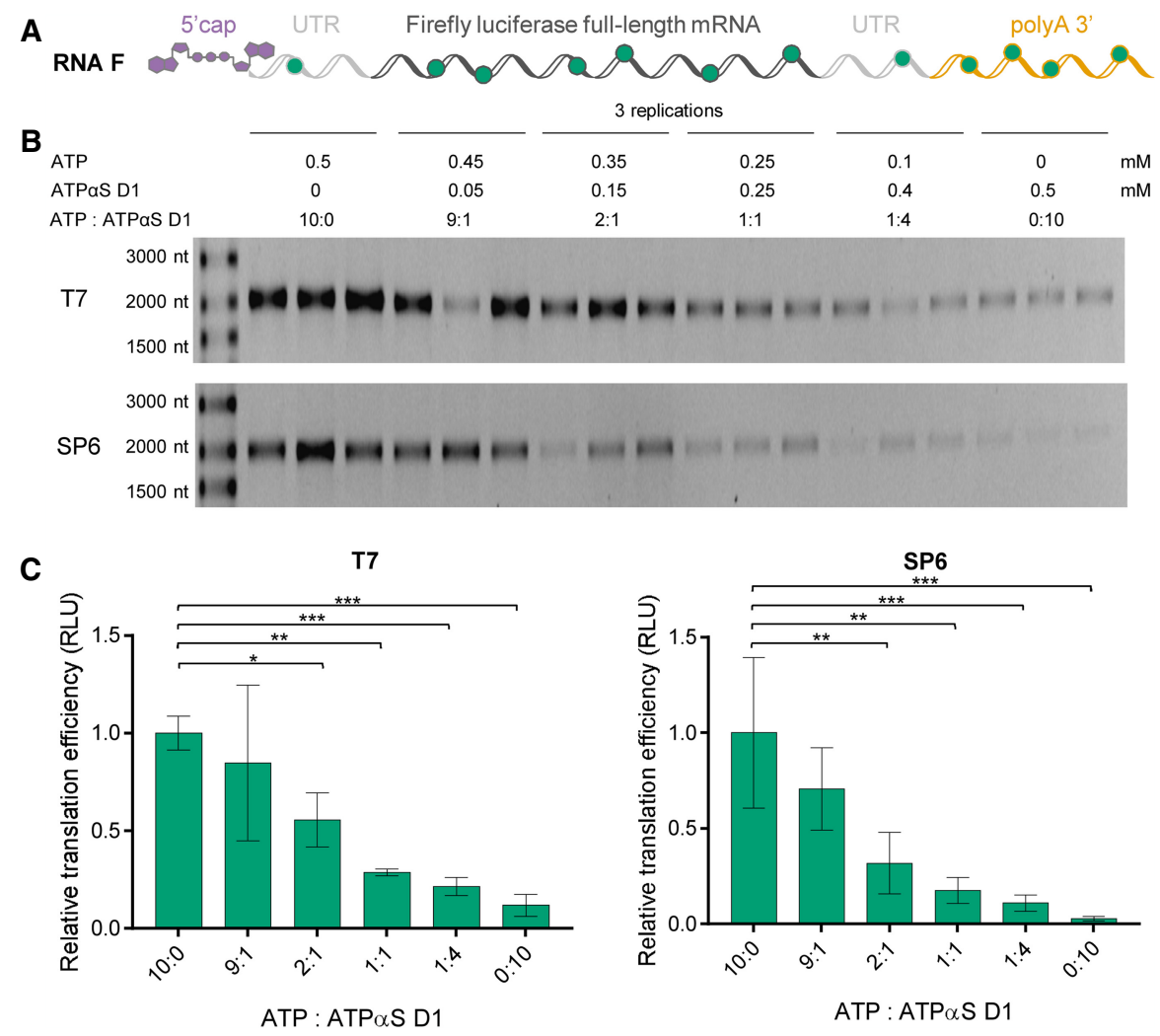

FIGURE 4. Analysis of homogeneity and translational properties of mRNAs uniformly modified with phosphorothioate moieties. (A) Schematic representation of Firefly luciferase (RNA F) in vitro transcribed (IVT) with T7 or SP6 RNA polymerase. Green dots represent phosphorothioate moieties randomly placed within the mRNA body. (B) RNA F variants cotranscriptionally $5^{\prime}$-capped with the cap analog ( $\beta$-S-ARCA D1) and obtained in the presence of the indicated ATP:ATP $\alpha$ S D1 molar ratios (10:0, 9:1, 2:1, 1:1, 1:4, or 0:10) are synthesized with T7 or SP6 RNA polymerase and purified on a silica membrane (NucleoSpin RNA Clean-up XS, Macherey-Nagel). The transcription yields and quality of transcripts are analyzed by electrophoresis on a 1\% agarose gel. (C) Translation efficiencies are tested in rabbit reticulocyte lysate (RRL [Promega]) using appropriate RNA F concentrations (3, 1.5, 0.75, and $0.375 \mathrm{ng} / \mu \mathrm{L}$ ) (see Materials and Methods for further details). Translation efficiencies are determined based on measured luminescence as a function of RNA F concentration. Slopes determined for different variants of RNA F are normalized to the slope of unmodified RNA F (10:0), calculated as the mean value from three independent experiments \pm standard deviation (SD). Statistical significance: (*) $P<0.05,(* *) P<0.01,(* *) P<0.001,(* * *) P<0.0001$ (one-way analysis of variance [ANOVA] with Dunnett's multiple comparison test). Only statistically significant differences are marked in the graph.

\section{PAP catalyzed the synthesis of phosphorothioate- modified poly(A) tails}

To achieve selective poly(A) tail modification of IVT RNAs, we used PAP from E. coli, a commercially available enzyme that specifically recognized the $3^{\prime}$ end of single-stranded RNA (ssRNA) and performed template-independent synthesis of single-stranded poly(A) tracts using ATP as a substrate. Previous reports have demonstrated incorporation of ATP $\alpha$ S into poly(A) tail using bovine PAP (Wittmann and Wahle 1997), but to the best of our knowledge, $E$. coli polymerase has not been investigated in this context; hence, we first tested its activity toward ATP $\alpha$ S D1 and D2. In a pilot experiment, polyadenylation reactions of RNA A $(35 \mathrm{nt})$ were performed. To this end, three PAP concentrations (1U, 2U, 4U) and either ATP alone, ATP:ATP $\alpha$ S in a 1:1 ratio, or ATP $\alpha$ S alone were tested (Fig. 5). The obtained products were initially analyzed by agarose gel electro- phoresis, which enabled visual estimation of the reaction efficiency and the dominant poly(A) tail length (Supplemental Fig. S8A, B). In the presence of ATP alone, polyadenylated RNAs of similar visual quality and dominant lengths between 300 and 500 nucleotides were formed in the presence of all tested PAP concentrations. In the presence of 1:1 ATP:ATP $\alpha$ S D1, the elongation of RNA was also observed, but the resulting RNAs appeared to be shorter and more homogenous, which indicated either a shorter length, disturbed migration due to modifications, or a smaller length distribution. In the presence of $100 \%$ ATP $\alpha$ S D1, the formed poly(A) tails migrated even faster (at the level corresponding to unmodified RNA). In the presence of the ATP:ATP $\alpha$ S D2 mix, the polyadenylation of RNA was clearly visible, and the resulting transcripts migrated only slightly faster than those obtained in the presence of ATP. In contrast, in the presence of $100 \%$ ATP $\alpha$ S D2, RNA elongation was not observed. Independently, 


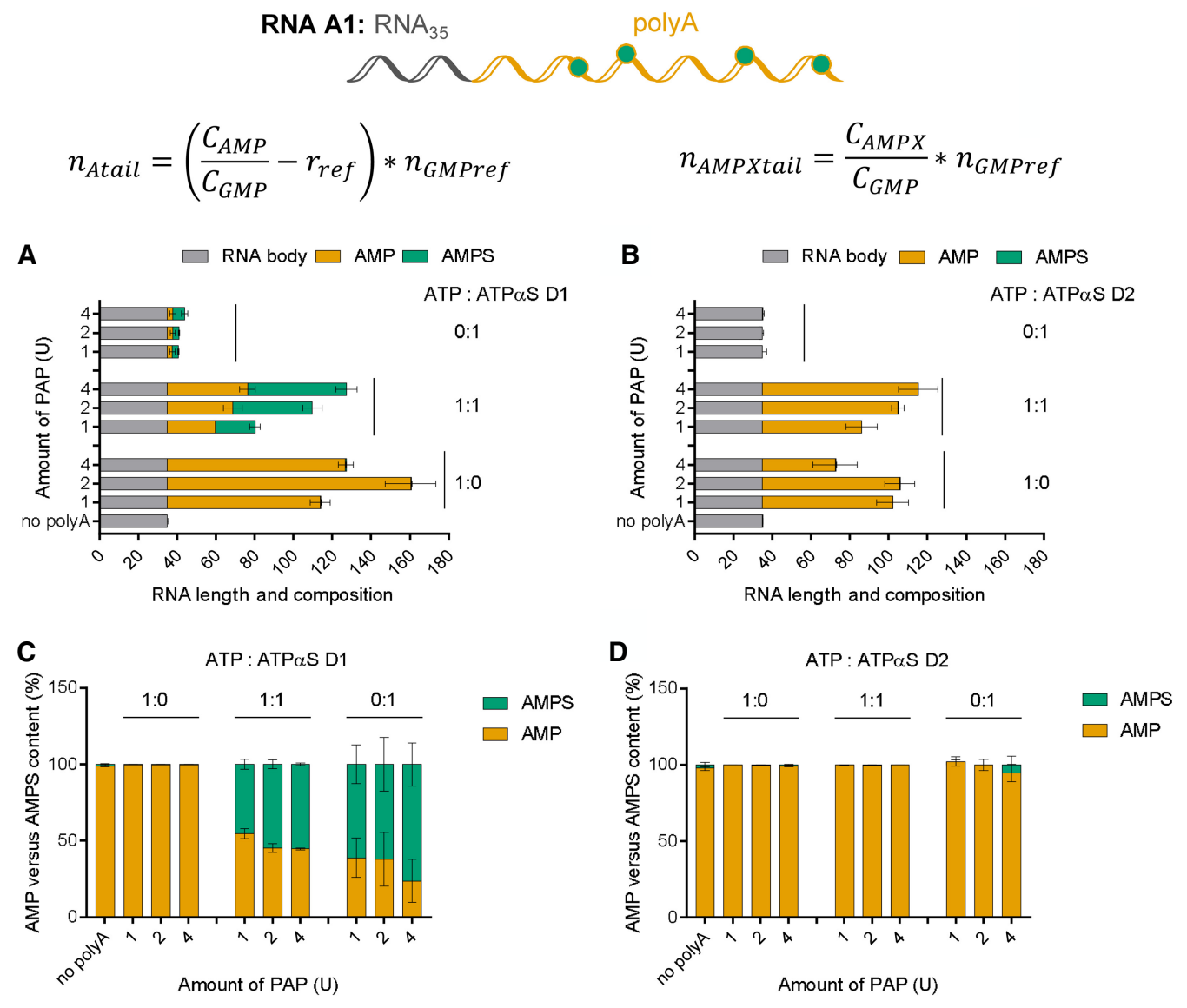

FIGURE 5. Poly(A) polymerase (PAP) incorporates ATP $\alpha$ S D1 in the presence of ATP to produce modified poly(A) tails. Analysis of short RNAs with poly(A) (RNA A1) tails added by PAP using different ATP:ATP $\alpha$ S ratios (1 mM). Short RNAs (RNA A) are obtained by SP6 polymerase. RNA A1 $(20 \mathrm{ng})$ is digested using snake venom phosphodiesterase (SVPDE) and Ccr4-Not transcription complex subunit 7 (CNOT7) for $1 \mathrm{~h}$ at $37^{\circ} \mathrm{C}$ (see Materials and Methods for further details). Data points represent mean values from triplicate experiments \pm standard error of the mean (SEM). $(A, C)$ Data obtained for ATP $\alpha S D 1,(B, D)$ data obtained for ATP $\alpha S$ D2. Data from a single agarose gel are shown on Supplemental Figure S8A,B. Poly(A) tail length and composition $(A, B)$ is determined based on liquid chromatography-tandem mass spectrometry (LC-MS/ $M S)$ quantification analysis and calculated based on the shown equation, wherein $C_{A M P, A M P X}$ is the concentration of $A M P$ or adenine analog, $C_{G M P}$ is the concentration of GMP, $r_{\text {ref }}$ is the ratio of AMP and GMP concentrations determined for the appropriate RNA lacking poly(A) tail $\left(r_{\text {fer }}=C_{A M P r e f} / C_{G M P r e f}\right), n_{G M P r e f}$ is the number of numbers $G s$ in the sequence, and $n_{\text {AMPXtail }}$ is the number of adenine nucleotide analogs in poly(A). The incorporation efficiency of ATP versus ATP $\alpha$ S D1 or D2 by PAP is then calculated $(C, D)$.

the obtained transcripts were digested using an SVPDE and CNOT7 mixture and the obtained products were analyzed by LC-MS/MS to determine RNA composition, poly (A) composition, and to estimate the average poly(A) tail length. The amounts of AMP and AMPS released from RNA were initially normalized to the GMP amount (Supplemental Fig. S8C,D). Knowing the concentrations and relative ratios of AMPS, AMP, and GMP in the samples, as well as the template sequence (specifically number of $A$ s and Gs in the template), the average poly(A) tail length was estimated using Equations 3 and 4 (Material and Methods; Fig. $5 A, B)$, which also enabled estimation of the poly(A) tail composition (Fig. 5C,D). AMPS was detected as a product of RNA degradation if ATP $\alpha$ S D1 was present in the polyadenylation reaction. RNAs obtained in the presence of ATP:ATP $\alpha$ S D1 released significant amounts of
AMPS, corresponding to an equally efficient incorporation of ATP and ATP $\alpha$ S D1 (Supplemental Fig. S8C). The average lengths of poly(A)s in those RNAs (45-95 nt) were comparable or only slightly shorter than those in corresponding RNAs obtained in the presence of ATP, and increased with increasing amounts of PAP (Fig. 5A). In contrast, poly(A) tails synthesized in the presence of $100 \%$ ATP $\alpha$ S D1 were notably shorter ( $5 \mathrm{nt})$. The quantification of products resulting from degradation of these indicated a notable amount ( 40\%) of AMP present in the poly(A) (Fig. 5B); however, this was likely due to a method limitation related to very short poly $(A)$ tails. Overall, we concluded that ATP $\alpha$ S D1 was accepted as a PAP substrate, but the incorporation process was efficient only if ATP was also present in the reaction mixture. If RNA was polyadenylated in the presence of the ATP:ATP $\alpha$ S D2 
mix, AMP was detected among the degradation products, while AMPS was not observed (Supplemental Fig. S8D). The average RNA lengths were comparable to those obtained in the presence of ATP (Fig. 5B). RNAs incubated with PAP in the presence of $100 \%$ ATP $\alpha$ S D2 did not contain poly(A) tails (Fig. 5D). This suggested that ATP $\alpha$ S D2 was not accepted as a substrate for PAP, similar to that for the T7 and SP6 polymerases.

The experiments also revealed a notable inconsistency in the lengths of poly(A) tails estimated by LC-MS/MS and PAGE analysis for RNAs obtained in the presence of ATP. To verify whether this arose from significant poly(A) tail length heterogeneity or an inaccuracy in our MS/MS method, we prepared a set of unmodified mRNAs (RNA F2) carrying poly(A) tails of various lengths (different poly (A) tail lengths were achieved by varying the duration of the polyadenylation reaction) and analyzed them using both methods (Supplemental Fig. S6). We found that RNA lengths determined by LC-MS/MS were around three times shorter than the RNA length estimated by electrophoretic analysis, but the correlation between the methods remained linear. Hence, we hypothesized that these differences between the methods arose from large RNA heterogeneity, which caused a significant difference between dominant and average mRNA lengths (Supplemental Fig. S6H).

\section{Phosphorothioate modifications decreased poly(A) tail susceptibility to deadenylation and slightly influenced protein expression levels in cells}

To study the effects of poly $(A)$ tail modification on mRNA stability and translation, we prepared unmodified mRNAs (RNA G and RNA H) and enzymatically added a poly(A) tail onto the $3^{\prime}$ end using PAP and phosphate-modified ATP analogs (Fig. 6A). We investigated various properties of $m$ RNAs with modified poly(A) tails, including poly(A) tail length, composition, susceptibility to deadenylation, and protein expression efficiency in mammalian cells. The DNA templates for in vitro transcription used in these experiments encoded a short 5' UTR sequence, followed by the Gaussia luciferase ORF and either a single or double $H$. sapiens $\beta$-globin 3' UTR sequence (RNA H and RNA G, respectively), and in the case of the reference mRNA (RNA I), an $A_{128}$ poly $(A)$ tail was encoded. To avoid interference from double-stranded RNA (dsRNA) impurities, the IVT mRNAs have been purified by RP HPLC prior to polyadenylation (Kariko et al. 2011; Sikorski et al. 2020). This procedure significantly increased the homogeneity of mRNAs used in the polyadenylation step, thereby facilitating LC-MS/MS analysis, since the presence of any additional RNAs in the PAP reaction mix affected the accurate concentration determination of total polyadenylated mRNA. RP HPLC-purified RNA G cotranscriptionally capped with ARCA (Supplemental Fig. S9A,B) was polya- denylated by PAP in the presence of either ATP or an ATP:ATP $\alpha$ S D1 mix (at 9:1, 4:1, 3:1, 2:1, and 1:1 molar ratios). The polyadenylation protocol was optimized (Supplemental Fig. S10) to yield RNA G1 with 200-250-nt long (based on agarose gel) poly $(A)$ tails containing a phosphorothioate modification as the predominant product. During initial polyadenylation experiments, we noted that high concentrations of ATP $\alpha$ S D1 in the polyadenylation reaction decreased the homogeneity of RNA G1 (Supplemental Figs. S11 and S12); therefore, the 1:1 molar ratio of ATP:ATP $\alpha$ S D1 was not exceeded.

The RNAs were first analyzed by LC-MS/MS to estimate the poly $(A)$ tail composition and average length. The results revealed that ATP $\alpha$ S D1 was efficiently incorporated into the poly(A) tail by PAP (Fig. 6B; Supplemental Table S3). The frequency of AMPS in the poly(A) tail, as determined using LC-MS/MS, was $~ 60 \%-70 \%$ of the expected phosphorothioate moiety content, according to the molar ratio of ATP:ATP $\alpha S$ D1 used in the polyadenylation reaction (Supplemental Table S3). The average poly(A) tail lengths determined by LC-MS/MS were similar to the lengths estimated by agarose gel electrophoresis (Fig. 6C; Supplemental Table S4). Moreover, the sensitivity of LC-MS/MS allowed for the analysis of the average poly (A) tail length of RNA G1, polyadenylated by PAP with a 1:1 molar ratio of ATP:ATP $\alpha$ S D1, whereas the length of the RNA G1 variant was difficult to estimate by electrophoretic analysis, due to heterogeneity (Fig. 6D; Supplemental Figs. S11 and S12).

To analyze the susceptibility to enzymatic degradation of modified poly(A) tails in mRNA, we set up a deadenylation assay using CNOT7 deadenylase. CNOT7 is one of two catalytic subunits in the human Ccr4-Not deadenylase complex responsible for deadenylation of mRNAs in the cytoplasm (Wahle and Winkler 2013). To this end, we performed time-course experiments to obtain the complete degradation of unmodified poly(A) tails, and to verify that recombinant CNOT7 was able to degrade only the poly $(A)$ tail and leave the mRNA body intact (Supplemental Fig. S13). Next, we used this protocol for deadenylation time-course experiments using RNA G1 variants with poly $(A)$ tails synthesized by PAP and selected ATP:ATP $\alpha$ S D1 molar ratios (9:1, 4:1, 3:1, 2:1, and 1:1) (Fig. 6D; Supplemental Figs. S11 and S12). We found that RNA G1 variants with poly(A) tails containing phosphorothioate modification were significantly less susceptible to CNOT7 deadenylase than unmodified RNA G1 (Fig. 6D, E; Supplemental Table S5). RNA G1 with a poly(A) tail obtained at a 9:1 ATP:ATP $\alpha$ S D1 ratio, which contained 6\% phosphorothioate moieties in the poly(A) tail (according to LC-MS/MS analysis), was degraded by CNOT7 at a rate three times slower than unmodified RNA G1 $\left(V_{0} 1.5\right.$ $\mathrm{nt} / \mathrm{min}$ and $\mathrm{V}_{0} 4.3 \mathrm{nt} / \mathrm{min}$, respectively). Further increases in the phosphorothioate content in the poly(A) tail to $13 \%, 15 \%$, and $23 \%$ corresponded to a deadenylation 


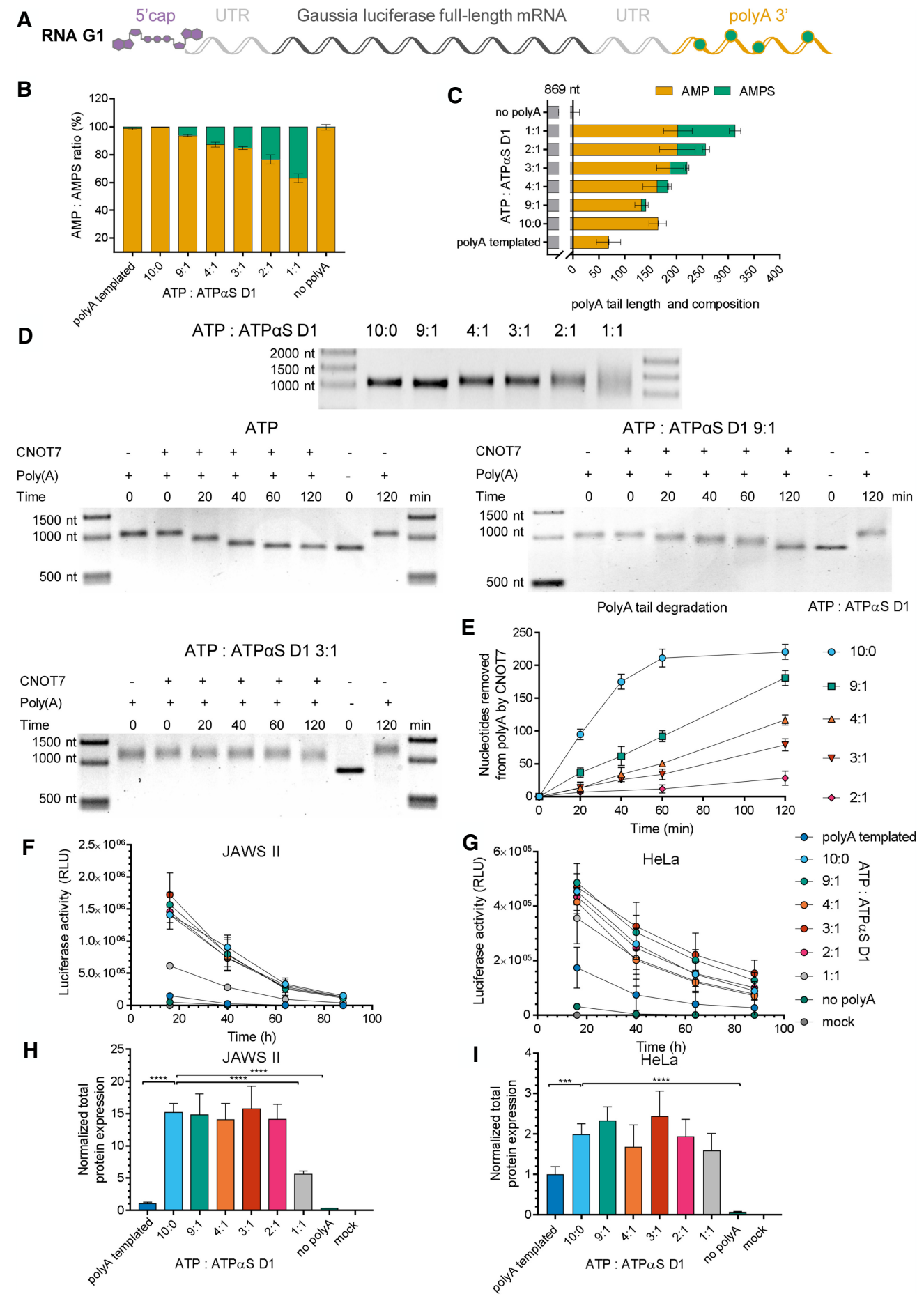

FIGURE 6. Analysis of mRNAs carrying phosphorothioate moieties within the poly(A) tail. (A) Schematic representation of the Gaussia luciferasecoding transcript, RP HPLC-purified and polyadenylated with poly(A) polymerase (PAP) in the presence of ATP or various mixtures of ATP:ATP $\alpha$ S D1 (9:1, 4:1, 3:1, 2:1, or 1:1 molar ratio). (B) RNA G1 poly(A) tail composition (the mean \pm standard error of the mean [SEM]), and (C) average poly (A) tail lengths (the mean \pm SEM) obtained from liquid chromatography-tandem mass spectrometry (LC-MS/MS). (D) Analysis of RNA G1 susceptibility to deadenylation. RNA G1 variants are incubated with Ccr4-Not transcription complex subunit 7 (CNOT7) deadenylase for 0-120 min, and the poly(A) tail degradation rate is analyzed on a 1\% agarose gel using Image Lab 6.0.1 Software (Bio-Rad). The length of the poly(A) tail at each time point is estimated as the difference between digested RNA G1 and RNA G (transcript before polyadenylation). (E) Susceptibility to deadenylation of RNA G1 polyadenylated with various ATP:ATP $\alpha$ S D1 ratios, estimated as the number of nucleosides removed by CNOT7 deadenylase at particular time points. (F-I) Translational properties of RNA G1 with phosphorothioate-modified poly(A) tails. Gaussia luciferase activity in the supernatant of $(F)$ JAWS II and $(G)$ HeLa cells, as measured 16, 40, 64, and 88 h after transfection with RNA G1. The cell medium was exchanged after each measurement. Data points represent mean values \pm the standard deviation (SD) of one biological replicate consisting of three independent transfections. Total protein expression (cumulative luminescence) over $4 \mathrm{~d}$ in (H) JAWS II and (I) HeLa cells calculated from the same experiment. Bars represent the mean value \pm SD normalized to RNA I (with a template-encoded $A_{128}$ poly(A) tail). Statistical significance: $\left({ }^{*}\right) P<$ $0.05,\left({ }^{* *}\right) P<0.01,\left({ }^{* *}\right) P<0.001,\left({ }^{* * *}\right) P<0.0001$ (one-way analysis of variance [ANOVA] with Dunnett's multiple comparison test). Only statistically significant differences are marked on the graph. 
rate reduced by 4.4-fold, 6.7-fold, and almost 20-fold, respectively (Supplemental Table S3).

We next investigated the influence of phosphorothioate moieties present in the poly $(A)$ on mRNA expression in living cells. To facilitate cell culture experiments, we used Gaussia luciferase as a reporter protein, since this type of luciferase is a secretory enzyme with a long half-life ( $\sim 6 \mathrm{~d})$, enabling straightforward monitoring of time-dependent mRNA expression by quantification of luminescence in cell culture medium (Wurdinger et al. 2008). Thus, variants of RNA G1 were transfected into two mammalian cell lines: HeLa and JAWS II, representing tumor and nontumor dendritic cells (DCs), respectively. Gaussia luciferase activity was measured over a period of $4 d$ (Fig. 6F,G). In both cell lines the total protein expression, reflected by luciferase activity, was similar for all tested mRNAs suggesting that phosphorothioate modification did not affect expression of the reporter protein (Fig. 6H, I). Interestingly, both in HeLa and JAWS II cells, protein expression for unmodified RNA G1 was more efficient than for the unmodified RNA I used as a reference, which was consistent with the presence of a shorter poly $(A)$ tail on RNA I (Fig. $6 \mathrm{H}, \mathrm{I})$. It was also noted that similar protein expression levels for most of the RNA G1 variants with phosphorothioate-modified poly $(A)$ tails did not correspond to decreased susceptibility to deadenylation, as determined with CNOT7 deadenylase.

These results altogether suggested that (i) using a mixture of ATP and ATP $\alpha$ S D1 for polyadenylation provided access to mRNAs with phosphorothioate-modified poly (A) tails; (ii) phosphorothioate moieties decreased poly(A) tail susceptibility to deadenylation by CNOT7; and (iii) protein expression levels in JAWS II cells did not change with increasing phosphorothioate moiety content in the poly(A) tails of transfected mRNA.

\section{Boranophosphate RNAs released AMPH as a degradation product}

After demonstrating the utility of the method to analyze RNA with a phosphorothioate moiety, we determined whether it could be adapted to analyze RNAs carrying boranophosphate modifications. The boranophosphate moiety has similar structural properties and net charge to phosphorothioate, and also exhibits nuclease resistance (Hall et al. 2004). During the optimization of the method, we observed that the synthesized heavy $\mathrm{AMPBH}_{3}$ was chemically unstable (Supplemental Fig. S14A,B) and, thus, could not be used as an internal standard. Furthermore, the main product of boranophosphate RNA degradation was not the expected $\mathrm{AMPBH}_{3}$, but adenosine $\mathrm{H}$ phosphonate (AMPH) (Supplemental Fig. S14C). As such, heavy AMPH was used as an internal standard for quantification of both $\mathrm{AMPH}$ and $\mathrm{AMPBH}_{3}$ in the samples. AMPH has similar fragmentation pathways to $\mathrm{AMPBH}_{3}$ (Strzelecka et al. 2017) but is chemically stable. Additionally, using heavy $\mathrm{AMPH}$ as an internal standard eliminated the problem of isotopic abundance of boron $\left(20 \%{ }^{10} \mathrm{~B}\right.$ and $80 \%$ $\left.{ }^{11} \mathrm{~B}\right)$, which decreased the sensitivity of detection.

To investigate the incorporation of boranophosphate analogs of ATP by PAP, we prepared RNAs that were depleted of adenosines throughout the sequence (RNA E). RNA E was obtained by in vitro transcription in the presence of T7 polymerase and subjected to a polyadenylation reaction, in which either 8-deutero ATP ( $\left.{ }^{\mathrm{D}} \mathrm{ATP}\right)$ was used instead of ATP, or a mixture of ${ }^{\mathrm{D} A T P: A T P} \alpha B \mathrm{H}_{3}$ (D1 or D2) was used. Polyadenylated RNA E1 was digested using a mixture of SVPDE and CNOT7, and the products were analyzed by LC-MS/MS (Fig. 7). AMPH was observed as the main unnatural product released from RNA E1, obtained in the presence of $A T P \alpha B H_{3}$ D1 (1:1 ${ }^{D} A T P: A T P \alpha B H_{3}$ D1 that was used for the polyadenylation reaction), while $\mathrm{AMPBH}_{3}$ was barely observed (Fig. 7C). RNAs obtained in the presence of $100 \% \mathrm{ATP}_{\mathrm{ABH}} \mathrm{D}$ 1 also released $\mathrm{AMPH}$, but the quantified poly $(A)$ tails were $\sim 10$-fold shorter compared to conditions including only ATP. Neither AMPH nor $\mathrm{AMPBH}_{3}$ were detected in samples generated from RNA E1 obtained using ${ }^{\mathrm{D}} \mathrm{ATP}$ and an $\mathrm{ATP} \alpha \mathrm{BH} \mathrm{H}_{3} \mathrm{D} 2$ in a 1:1 ratio, which indicated that $A T P \alpha B H_{3} D 2$ was not incorporated by PAP. Compared to ATP $\alpha$ S D1, ATP $\alpha B H_{3}$ D1 seemed to be incorporated with lower frequency; $40 \%$ AMPS (Supplemental Fig. S5) and $20 \%$ AMPH (Fig. 7) were detected when a 1:1 ratio of ATP and ATP $\alpha$ X isomer D1 was used for polyadenylation. Overall, the results indicated that only ATP $\alpha \mathrm{BH}_{3}$ D1 was recognized as a substrate by PAP, but the polymerization reaction was less efficient than that for ATP and ATP $\alpha$ S D1.

\section{Boranophosphate modifications had a moderate influence on poly(A) tail susceptibility to deadenylation and diminished protein expression levels in cells}

To study translational properties of mRNAs with boranophosphate-modified poly(A) tails, RNA H was obtained by transcription in vitro, purified by RP HPLC (Supplemental Fig. S9C), and polyadenylated with PAP in the presence of ATP, ATP $\alpha B H_{3}$ D1, or ATP:ATP $\alpha B H_{3}$ D1 mixtures (at 49:1, 24:1, 14:1, 9:1, 5:1, 3:1, and 1:1 molar ratios) (Fig. 8A). RP HPLC-purified RNA I, carrying a template-encoded poly(A) tail, was used as a reference in this experiment. The initial experiments revealed that the increased concentration of $A T P \alpha B H_{3} D 1$ in the reaction mix resulted in shorter poly(A) tails (Supplemental Fig. S10C), which was consistent with the results obtained for RNA E polyadenylated with $A T P \alpha B H_{3}$ D1 (Fig. 7). To obtain RNA H1 variants with poly $(A)$ tails of similar lengths, the polyadenylation protocol (previously set up for RNA G) was modified by adjusting the incubation time with PAP. Using this approach, we obtained RNA H1 variants with 200-250 nt poly(A) 


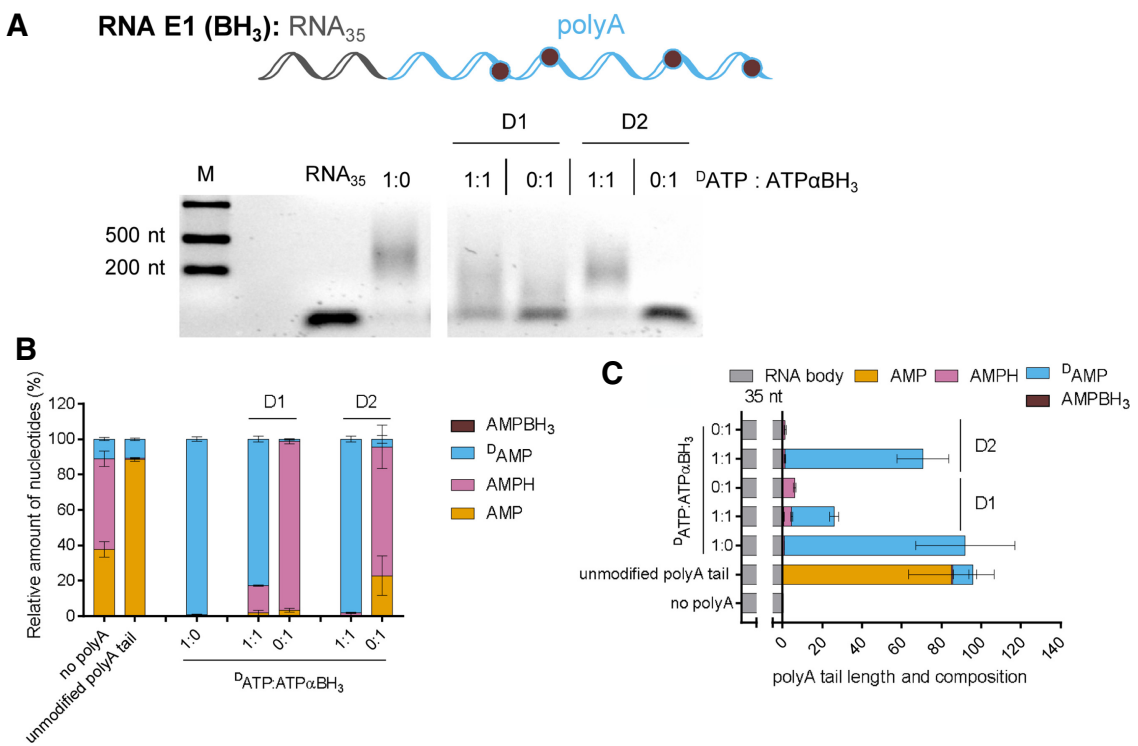

FIGURE 7. Boranophosphate RNAs release adenosine $H$-phosphonate (AMPH) as a degradation product. Analysis of short RNAs (RNA E1) (with $U$ instead of $A$ in the sequence) with poly(A) tails added by poly(A) polymerase (PAP) using different ${ }^{\mathrm{D}}$ ATP/ATP analog ratios. ${ }^{\mathrm{D}} \mathrm{ATP}$ includes $10 \%$ ATP, which is taken into account during data analysis. RNAE1 is digested using snake venom phosphodiesterase (SVPDE) and Ccr4-Not transcription complex subunit 7 (CNOT7) for $1 \mathrm{~h}$ at $37^{\circ} \mathrm{C}$ (see Materials and Methods for further details). (A) Data shown are from a single agarose gel. (B) Amount of nucleotides (the mean \pm standard error of the mean [SEM]) after RNA degradation, as determined by liquid chromatography-tandem mass spectrometry (LC-MS/ MS) normalized to guanosine monophosphate (GMP). (C) Poly(A) tail length (the mean \pm SEM) calculated based on the concentration of nucleotides released from the RNA and RNA body sequence (Materials and Methods).

tails (based on an agarose gel). The obtained RNA H1 variants were highly homogenous (Supplemental Figs. S15S17), regardless of the ATP:ATP $\alpha B \mathrm{H}_{3}$ D1 ratio used for polyadenylation; therefore, we also prepared an RNA H1 variant with a poly(A) tail synthesized in the presence of $100 \%$ ATP $\alpha \mathrm{BH}_{3}$ D1 (Supplemental Figs. S15 and S16).

To determine the composition and average poly $(A)$ tails lengths, different variants of RNA H1 were enzymatically degraded with SVPDE and CNOT7 ribonucleases, and the mixtures of the obtained NMPs were analyzed using LC-MS/MS (Fig. 8B,C). The determined frequencies for ATP $\alpha B H_{3}$ D1 were lower than that for ATP $\alpha$ S D1, especially for RNA $\mathrm{H} 1$ variants polyadenylated by PAP at high concentrations of $A T P \alpha B H_{3}$ D1 (Figs. 6B and 8B; Supplemental Table S3).

To evaluate the influence of boranophosphate modification on the poly $(A)$ tail susceptibility to deadenylation, the transcripts were subjected to degradation by CNOT7 and the reaction progress was monitored using agarose gel electrophoresis. Based on the determined poly(A) tail lengths as a function of time, deadenylation rates were determined for each RNA (Fig. 8E). The degradation rate for unmodified RNA H1 was similar to the previously analyzed unmodified RNA G1 ( $V_{0} 4.1 \mathrm{nt} / \mathrm{min}$ and $V_{0} 4.3 \mathrm{nt} / \mathrm{min}$, respectively) (Supplemental Tables S5 and S6), suggesting that the RNA body sequence had no influence on susceptibility to CNOT7. RNA H1, with a boranophosphate-modified poly(A) tail, was more susceptible to deadenylation by CNOT7 than its counterparts containing phosphorothioate moieties at similar frequencies (Figs. 6D,E and 8D,E; Supplemental Table S3). Interestingly, RNA H1 polyadenylated with $100 \% \quad \mathrm{ATP}_{\alpha} \mathrm{BH}_{3}$ D1 was degraded faster than RNA G1 polyadenylated by PAP at a 9:1 molar ratio of ATP: ATP $\alpha$ S D1 (according to LC-MS/MS, the phosphorothioate moiety content was $6 \%$ ). These results showed that phosphorothioate modification had greater potential to affect the deadenylation process than a boranophosphate moiety.

To analyze the translational properties of RNA H1 polyadenylated with selected ATP:ATP $\alpha B H_{3}$ D1 molar ratios, JAWS II and HeLa cells were transfected with RNA $\mathrm{H} 1$ variants and RNA I, and the activity of Gaussia luciferase secreted into the medium was measured over time (Fig. 8F,G). It was found that total protein expression levels decreased with increasing boranophosphate content (Fig. 8H,I). Even for the lowest tested ATP:ATP $\alpha B H 3$ D1 ratio (49:1), the translational efficiency was slightly compromised. This result suggested that the boranophosphate modification was less compatible with mRNA expression in vivo than phosphorothioate.

\section{DISCUSSION}

In this work, we contributed to the development of chemically modified mRNAs with superior biological properties. So far, properties of therapeutic mRNAs were modulated by the use of chemical $5^{\prime}$ cap analogs, introducing unnatural nucleosides into the mRNA body, switching between various $5^{\prime}$ and $3^{\prime}$ UTR elements, or by optimizing codons. It has been previously demonstrated that replacing one of the four nucleotides used for in vitro transcription by its phosphorothioate analog produces mRNAs that are efficiently expressed in a prokaryotic cell-free translation system (Ueda et al. 1991). However, prokaryotic mRNAs do not contain the $5^{\prime}$ and $3^{\prime}$ end stabilizing elements ( $5^{\prime}$ cap and poly(A) tail, respectively), characteristic for eukaryotic mRNAs, and are processed by quite different translational machineries (Kozak 2005), so the biological consequences of phosphate modifications may be different for these two systems. We have previously shown that an O-to-S or O-to- 


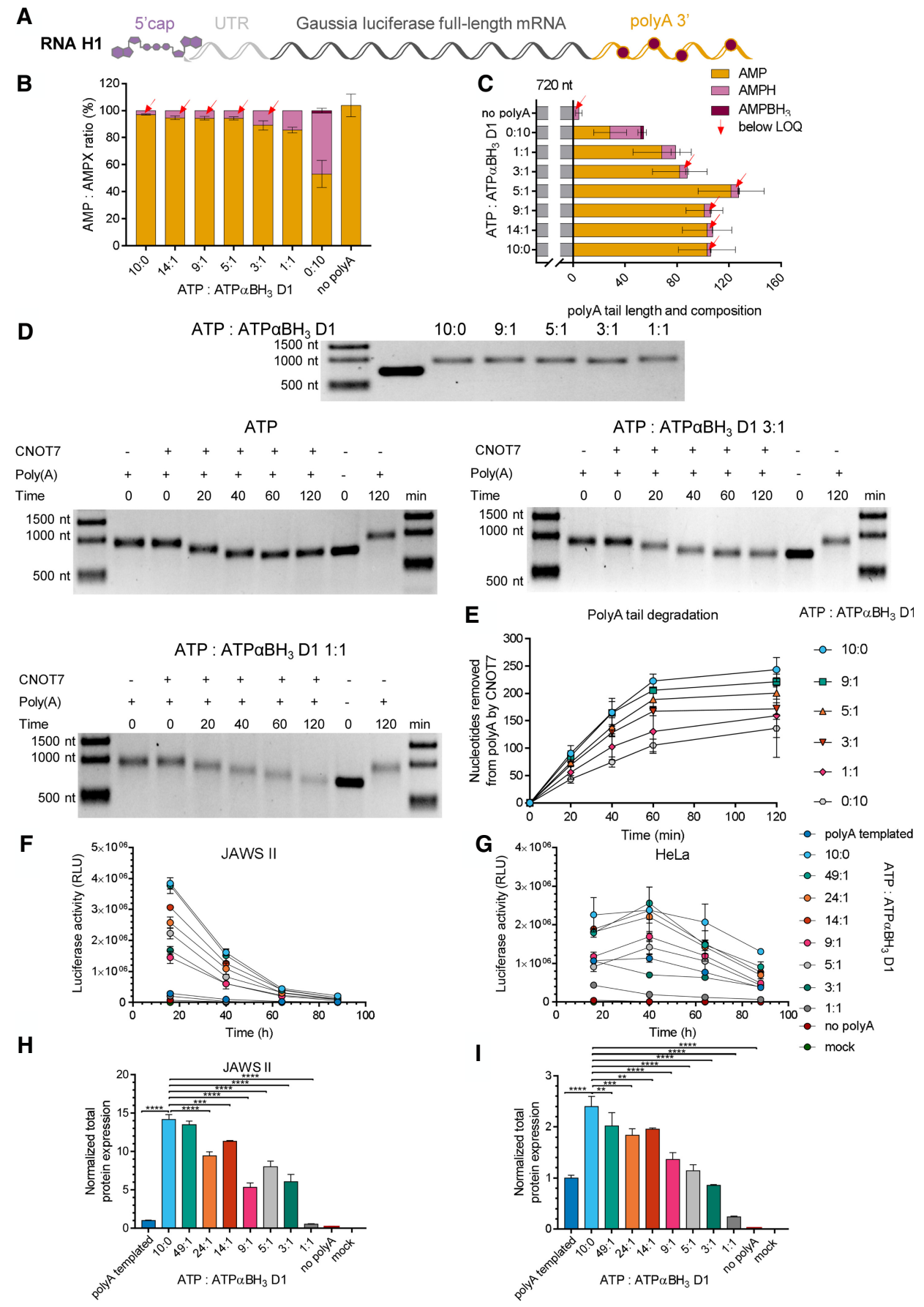

FIGURE 8. Analysis of mRNAs carrying boranophosphate moieties within the poly(A) tail. (A) Schematic representation of the Gaussia luciferasecoding transcript, RP HPLC-purified and polyadenylated with poly(A) polymerase (PAP) in the presence of ATP, ATP $\alpha B H_{3} D 1$ alone, or various mixtures of ATP:ATP $\alpha B_{3}$ D1 (14:1, 9:1, 5:1, 3:1, or 1:1). (B) RNA H1 tails composition (the mean \pm standard error of the mean [SEM]) and (C) average poly $(A)$ tail lengths (the mean \pm SEM) obtained from LC-MS/MS. (D) Analysis of RNA H1 susceptibility to deadenylation. RNA H1 variants are incubated with CNOT7 deadenylase for 0-120 min, and the RNA length is analyzed on a 1\% agarose gel using Image Lab 6.0.1 Software (Bio$\mathrm{Rad}$ ). The length of the poly(A) tail at each time point is estimated as the difference between digested RNA H1 and RNA H (transcript before polyadenylation). (E) Susceptibility to deadenylation of RNA H1 polyadenylated with various ATP:ATP $\alpha B H_{3}$ D1 ratios, estimated as the number of nucleosides removed by CNOT7 deadenylase at particular time points. (F-I) Translational properties of RNA H1 with boranophosphate-modified poly(A) tails. Gaussia luciferase activity in the supernatant of (F) JAWS II and (G) HeLa cells, as measured 16, 40, 64, and $88 \mathrm{~h}$ after transfection with RNA H1. The cell medium was exchanged after each measurement. Data points represent mean values \pm standard deviation (SD) of one biological replicate consisting of three independent transfections. (H) Total protein expression (cumulative luminescence) over $4 \mathrm{~d}$ in JAWS II and (I) HeLa cells calculated from the same experiment. Bars represent the mean value \pm SD normalized to RNA I (with a template-encoded $A_{128}$ poly $(A)$ tail). Statistical significance: $\left(^{*}\right) P<0.05,\left(^{* *}\right) P<0.01,\left(^{* *}\right) P<0.001,\left(^{* * * *}\right) P<0.0001$ (one-way analysis of variance [ANOVA] with Dunnett's multiple comparison test). Only statistically significant differences are marked on the graph. 
$\mathrm{BH}_{3}$ substitution within the $\beta$-phosphate of the mRNA cap confers beneficial translational properties to mRNA by stabilizing the interaction with elF4E and blocking $5^{\prime} \rightarrow 3^{\prime}$ degradation (Kowalska et al. 2014; Grudzien-Nogalska and Kiledjian 2017). To the best of our knowledge, the presence of $\mathrm{O}$-to-X substitutions within the eukaryotic mRNA body has not been studied. Here, we investigated whether the presence of $\mathrm{O}$-to-S or $\mathrm{O}$-to- $\mathrm{BH}_{3}$ substitutions within the $5^{\prime}, 3^{\prime}$-phosphodiester bonds of mRNA influenced translational properties in mammalian expression systems. We envisaged that such modifications may have beneficial effects on mRNA stability, primarily by blocking the degradation from the $3^{\prime}$ end (the $\operatorname{poly}(A)$ tail). To test this hypothesis, we first developed a method for quantitative assessment of incorporation of ATP analogs modified at the $\alpha$-phosphate into RNA by polymerases, which relied on exhaustive degradation of the transcripts by $3^{\prime}$ nucleases followed by LC-MS/MS analysis of the resulting nucleoside monophosphates and their phosphate-modified analogs. The phosphorothioate-containing RNAs released AMPS as the main degradation product, whereas the boranophosphate RNAs released AMPH instead of $\mathrm{AMPBH}_{3}$, which was unexpected, but did not hamper method development. The key factor during method optimization was the adjustment of degradation conditions to ensure complete RNA degradation without desulfurization of AMPS to AMP. The method was successfully used to analyze both short and long RNAs, with the phosphorothioate quantification limit found to be $0.03 \mu \mathrm{M}$. The incorporation assessment of ATP $\alpha$ S diastereomers (D1 $=S_{P}$ and D2 $=R_{P}$ ) by SP6 and T7 polymerases revealed that only the $S_{P}$ isomer of ATP $\alpha$ S served as the unnatural substrate for these polymerases, albeit not as efficiently as ATP, which was most evident from the decreased transcription yield when ATP $\alpha$ S D1 was used as the only adenine-containing substrate (Figs. 3 and 4; Supplemental Fig. S4). The $R_{\mathrm{P}}$ isomer of ATP $\alpha$ S was neither substrate nor inhibitor of the polymerases. These findings are in good agreement with literature reports on stereo-preferences of RNA polymerases (Eckstein et al. 1976; Burgers and Eckstein 1978; Armstrong et al. 1979; Gish and Eckstein 1988; Gaur and Krupp 1993; Eckstein and Thomson 1995). Degradation of RNAs obtained with a deuterated ATP analog ( ${ }^{\mathrm{A}} \mathrm{ATP}$ ) and either $\mathrm{ATP} \alpha \mathrm{S}$ D1 or $\mathrm{ATP} \alpha \mathrm{BH}_{3} \mathrm{D} 1$ at a $1: 1$ ratio under optimized conditions revealed less than $10 \%$ of nondeuterated AMP ( 7\% for phosphorothioate and $2 \%$ for boranophosphate), indicating that more than $90 \%$ of the modified analyte remained intact in the presence of $5^{\prime}$ nucleases (Fig. 7; Supplemental Fig. S5). Following these initial experiments, we set out to evaluate biological properties of mRNAs IVT in the presence of ATP analogs. We found that in the presence of ATP $\alpha$ S D1:ATP mixtures, IVT mRNAs containing template-encoded poly(A) tails were synthesized significantly less efficiently by both T7 and SP6 polymerase than in the presence of ATP, which limited the amount of mRNA available to further biochemical analyses. Moreover, the yields of protein expression (firefly luciferase) per nanogram of RNA measured in RRLs were also significantly lower than those for unmodified mRNAs. This is in contrast to prokaryotic systems, where the detrimental effect of mRNA body modification within phosphorothioate groups on translation of prokaryotic mRNA has been reported only if more than one NTP was replaced with NTP $\alpha$ S (Ueda et al. 1991). It should be noted, however, that the firefly luciferase-based assay used in our work detected only functional proteins, so shortened, misfolded, or mutated proteins may be formed, but were not detected. We hypothesized that phosphorothioate modifications within the UTR and ORF may impair ribose movement necessary for efficient translation. Therefore, we focused on modifying mRNA exclusively within the poly $(A)$ tails. Modified poly $(A)$ tails were introduced into IVT mRNA by the use of PAP from E. coli as a specific tailing enzyme. The same enzyme has been recently used to fluorescently label polyadenylated mRNA (Anhauser et al. 2019), but to the best of our knowledge, it has never been studied with phosphate-modified ATP analogs. The poly(A) tail lengths estimated by LC-MS/ MS were slightly shorter than those obtained with ATP under the same conditions. However, the data on the length should be interpreted carefully due to differences in RNA homogeneity observed for different RNA types and compositions. The fact that poly(A) tails obtained in the presence of PAP are highly heterogeneous has been previously reported (Yehudai-Resheff and Schuster 2000; Balbo and Bohm 2007). The incorporation of ATP $\alpha$ X D1 analogs was even less efficient in the absence of ATP.

The poly(A) tail impacts mRNA stability and translation efficiency via interaction with PABPs (Coller et al. 1998; Dodson and Shapiro 2002). Recent studies highlight a correlation between poly(A) tail length and translation of mRNA (Lima et al. 2017). Therefore, to analyze P-mod mRNA susceptibility to deadenylation in vitro and expression in living cells, we prepared mRNAs of similar poly(A) tails lengths (200-250-nt long) (Brawerman 1981). This was confirmed using both electrophoretic analysis and LC-MS/MS (Figs. 6 and 8). The susceptibility of mRNAs with phosphate-modified $\operatorname{poly}(A)$ tails to deadenylation by recombinant human CNOT7, which is one of the two catalytic subunits of Ccr4-Not complex (Miller and Reese 2012), was analyzed by gel electrophoresis (Figs. 6 and 8). We observed a significantly decreased susceptibility of mRNAs polyadenylated by PAP to deadenylation in the presence of ATP:ATP $\alpha$ S D1 mixtures. The degradation rates correlated qualitatively with the modification frequency (the higher the phosphorothioate content, the more stable the poly(A)). In contrast, boranophosphate modification only moderately affected susceptibility to CNOT7; the boranophosphate mRNA was 2 2.7-fold more susceptible to CNOT7 than a phosphorothioate 
mRNA of analogous composition. As the structural information elucidating the atomic details of the poly $(A)$ recognition by CNOT7 deadenylase is not available, it is difficult to speculate on the different stabilities of phosphorothioate and boranophosphate RNAs. Nonetheless, the differences in size, charge distribution, and solvation between a sulfur atom and a borano group affect hydrogen bonding, metal ion coordination potential (Jaffe and Cohn 1978; Pecoraro et al. 1984), and poly(A) topology, which in turn leads to various rearrangements of the CNOT7 active site upon substrate binding and differentially affects catalytic efficiency. The differentiation between these two modifications by CNOT7 may guide a better understanding of substrate specificity of deadenylases, and hence phosphate-modified poly(A) tails may serve as useful research tools.

To investigate whether poly(A) stability in vitro impacts protein biosynthesis in living cells, we measured the expression of Gaussia luciferase-encoding mRNAs containing variously modified poly(A) tails in two cell lines: HeLa (cancer cells) and JAWS II (dendritic cells, relevant in the context of mRNA-based vaccines). In both cell lines, phosphorothioate-modified poly(A) tails did not affect protein expression, regardless of the phosphorothioate moiety content in the poly(A) tail. This indicated that the phosphorothioate modification was compatible with translation in living cells, albeit it did not provide any evident biological effect, at least for the studied poly(A) tail compositions. In contrast, the presence of a boranophosphate moiety in poly(A) tails clearly correlated with a decline in protein expression levels. Overall, the data from both in vitro and cell culture experiments indicated that only the phosphorothioate modification stabilized the poly $(A)$ tail and efficiently supported translation. It remains to be determined how this modification affects interaction with PABPs. As demonstrated by Deo et al. (1999) and Safaee et al. (2012), PABP-oligo $A_{11}$ complex formation is mostly driven by extensive interactions of PABPs with adenines, engaging hydrogen bonds, van der Waals contacts, and base stacking. The sugar-phosphate backbone is less extensively probed by PABP amino acid side chains; therefore, potentially providing steric freedom for substitutions of the nonbridging oxygen atoms of the $\alpha$-phosphate (Deo et al. 1999; Safaee et al. 2012). Nevertheless, phosphorothioate and boranophosphate modifications can affect three-dimensional organization of the poly $(A)$ tail; therefore, influencing the dynamics of its recognition by PABPs (Borman et al. 2000; Vicens et al. 2018). Finally, it should be emphasized that the poly(A) tails obtained by the reported enzymatic procedure were heterogeneous not only in length, but also in composition. Random incorporation of ATP $\alpha$ S resulted $P$, which were inseparable and thus analyzed together as one sample. However, it is likely that these variants might quite significantly differ in biological properties. The fact that the average translation for these variants was comparable to unmodified mRNA, did not exclude the existence of modification "sweet spots" characterized by superior biological properties. Although currently available synthetic methods do not allow for fully controllable incorporation of phosphate modification into $\operatorname{poly}(A)$, our results indicate that this field is worth further exploration in the context of therapeutic mRNA.

Overall, our research is the first step toward understanding the impact of sugar-phosphate mRNA backbone modifications on the biological properties of these molecules. The mRNA synthesis and analysis protocols reported here may find application in basic studies dissecting mRNA translation and degradation, as well as studying properties of mRNA-based therapeutics. Intriguingly, phosphorothioate modification has been recently identified in rRNA in E. coli, L. lactis, and HeLa cells, which might spike even higher interest in the properties of phosphatemodified RNAs in the future (Wu et al. 2020).

\section{MATERIALS AND METHODS}

\section{Chromatographic and mass spectrometric conditions}

\section{Instrumentation}

All LC-MS/MS analyses were performed on a QTRAP 3200 (AB Sciex) system consisting of an electrospray ion source and triple quadrupole/linear ion trap analyzer. The instrument was coupled with an Agilent Technologies high-performance liquid chromatography (HPLC) system equipped with 1260 Bin Pump and degasser, 1260 ALS autosampler, and 260 TCC column oven. Analyst 1.6 software was used for system control, data acquisition, and data processing.

\section{General information}

MS-grade reagents (methanol, acetonitrile, ammonium acetate, and other solvents) and starting materials (such as unmodified nucleosides and ATP) and chemical reagents, including $\mathrm{N}, \mathrm{N}$-dimethylhexylamine $(\mathrm{DMH})$ and $97 \% \mathrm{H}_{2}^{18} \mathrm{O}$ were purchased from commercial sources. Nucleotide analogs were synthesized by published methods (Kowalska et al. 2007, 2008; Strenkowska et al. 2012). SP6 and T7 polymerases were purchased from Thermo Fisher Scientific. PAP was purchased from Lucigen. Snake venom phosphodiesterase (SVPDE) was purchased from Sigma-Aldrich. Ccr4-Not transcription complex subunit 7 (CNOT7) was purified as described in the Materials and Methods.

If necessary, the compounds were purified by means of analytical HPLC or semi-preparative reversed-phase (RP) HPLC. Analytical HPLC (Series 1200; Agilent Technology) was performed using a Supelcosil LC-18-T HPLC column $(4.6 \times 250$ $\mathrm{mm}, 5 \mu \mathrm{m}$, flow rate $1.3 \mathrm{~mL} / \mathrm{min}$ ) with a linear gradient of $0 \%-$ $50 \%$ methanol in $0.05 \mathrm{M}$ ammonium acetate buffer ( $\mathrm{pH}$ 5.9) for $15 \mathrm{~min}$ and UV detection at $254 \mathrm{~nm}$. Semi-preparative HPLC was performed on the same apparatus equipped with a Discovery RP Amide C-16 HPLC column $(25 \mathrm{~cm} \times 21.2 \mathrm{~mm}$, $5 \mu \mathrm{m}$, flow rate $5.0 \mathrm{~mL} / \mathrm{min}$ ) with a linear gradient of $0 \%-100 \%$ 
acetonitrile in $0.05 \mathrm{M}$ ammonium acetate buffer ( $\mathrm{pH}$ 5.9) for 120 min with UV detection at $260 \mathrm{~nm}$.

\section{Liquid chromatography}

Chromatographic separation of nucleoside 5'-monophosphates (NMPs) was achieved on an Eclipse XDB-C18 analytical column (5.0 $\mu \mathrm{m}, 4.6 \mathrm{~mm} \times 150 \mathrm{~mm}$, Agilent) equipped with an Eclipse XDB-C18 analytical guard column $(5.0 \mu \mathrm{m}, 4.6 \times 12.5 \mathrm{~mm})$. The gradient mobile phase contained the $\mathrm{DMH}$ ion pair reagent (Auriola et al. 1997) and comprised two eluents: eluent $A$, which was $20 \mathrm{mM}$ aqueous $\mathrm{DMH}$ adjusted to $\mathrm{pH} 4.8$ with formic acid, and eluent $B$, which was a 1:1 (v/v) mixture of acetonitrile and aqueous $20 \mathrm{mM} \mathrm{DMH}$ adjusted to $\mathrm{pH} 4.8$ with formic acid. The elution was performed at room temperature (RT) and at a flow rate of $700 \mu \mathrm{L} \mathrm{min}^{-1}$. The gradient was optimized to obtain sufficient chromatographic separation of all analytes of interest (AMP, AMPS, and GMP). The optimal gradient was $0 \%-100 \%$ eluent $B$ in $15 \mathrm{~min}$.

\section{Mass spectrometry}

The analytes in the HPLC eluate were monitored by MS in multiple reaction monitoring (MRM) mode. MS conditions for individual analytes and internal standards were optimized directly from the syringe pump. The optimization was performed using 400 $\mu \mathrm{M}$ solutions of individual NMPs and their respective isotope-labeled internal standards. Optimizations and analyses have been performed in negative ionization mode to maximize the number of fragmentation reactions (Strzelecka et al. 2017). The general ion source conditions used in all experiments were as follows: turbo ion-spray voltage: $-4500 \mathrm{~V}$, temperature: $300^{\circ} \mathrm{C}$, curtain gas: 30 psi, ion source gas 1: 30 psi, and ion source gas 2: 25 psi. The MRM transitions and MS conditions for individual NMPs and isotope-labeled internal standards are depicted in Supplemental Table S1.

\section{Method validation}

\section{Calibration curves}

The calibration curves were prepared by spiking known concentrations $(0.01-50 \mu \mathrm{M})$ of NMP and a constant concentration of isotopically labeled internal standard $(2 \mu \mathrm{L}, 10 \mu \mathrm{M}$; the final concentration in $20 \mu \mathrm{L}$ samples was $1 \mu \mathrm{M}$ ) into reaction solution (SVPDE buffer, $1 \mathrm{mM}$ magnesium chloride $\left[\mathrm{MgCl}_{2}\right], 5 \mathrm{mM}$ Tris, $\mathrm{pH}$ 8,8, and deactivated SVPDE) (Supplemental Fig. S3). Calibration curves were built by fitting the analyte-to-internal standard concentration ratio versus the analyte-to-internal standard peak area ratio using linear regression analysis $y=a x+b$, where the a parameter is the slope and $b$ is the $y$-intercept. The limits of quantification are depicted in Supplemental Table S2.

\section{Degradation conditions}

A typical RNA degradation reaction $(20 \mu \mathrm{L})$ was performed at $37^{\circ} \mathrm{C}$ for $1 \mathrm{~h}$ and contained either (i) 20 ng RNA RN $_{35}$ (RNA A, RNA $B$ and RNA C), $3000 \mathrm{ng} / \mathrm{mL}$ SVPDE (Sigma-Aldrich) in SVPDE buffer (1 $\mathrm{mM} \mathrm{MgCl}_{2}, 5 \mathrm{mM}$ Tris, $\mathrm{pH}$ 8,8); or (ii) $20 \mathrm{ng} \mathrm{RNA}_{35}$ with poly(A) (RNA A1 and RNA E1) or 40 ng (RNA F2 and RNA G1) (or more $120 \mathrm{ng}$, in the case of the boranophosphate modification, RNA H) mRNA, 9000 ng/mL SVPDE (Sigma-Aldrich), 1 mg/ $\mathrm{mL}$ CNOT7 enzyme, buffer $(5 \mathrm{mM} \mathrm{MgCl} 2,10 \mathrm{mM}$ Tris, $\mathrm{pH}$ 8.0, $50 \mathrm{mM}$ potassium chloride [KCl], $10 \mathrm{mM}$ dithiothreitol [DTT]). The reactions were quenched by snap-freezing in liquid nitrogen, followed by heating at $95^{\circ} \mathrm{C}$ for $5 \mathrm{~min}$, and snap-freezing in liquid nitrogen again. Samples after degradation were analyzed using LC-MS/MS. To each sample containing $20 \mathrm{ng} / 40 \mathrm{ng} / 120 \mathrm{ng}$ of degraded RNA, $1 \mu \mathrm{M}$ isotopically labeled internal standard was added. The enzyme amount was initially optimized on model RNAs to ensure degradation to single mononucleotides and lack of their further degradation (which was observed by MS at high enzyme concentrations, Fig. 2F,G; Supplemental Fig. S4). During optimization, the post-degradation reaction mixtures were analyzed by $15 \%$ polyacrylamide gel electrophoresis (PAGE). If any undigested RNA fragments were noticeable, the enzyme amount was increased.

\section{Calculations-concentrations and poly(A) tail length}

Concentrations of analytes $\left(C_{A}\right)$ were calculated based on calibration curve parameters $(a, b)$, internal standard concentration $\left(C_{I S}\right)$, and signal intensities $\left(I_{A}\right.$-analyte intensity, $I_{I S}$-internal standard intensity); $b$ was fixed to 0.0 (Equation 1).

$$
C_{A}=\frac{I_{A}}{I_{I S} * a} * C_{I S}
$$

Concentrations of AMP in the poly(A) tail were calculated according to Equation 2.

$$
C_{A M P t a i l}=C_{A M P \text { total }}-r_{\text {ref }} * C_{G M P}
$$

where $r_{\text {ref }}$ is a value obtained from the appropriate RNA fragment without the poly $(A)$ and is the ratio of the concentration of AMP and GMP $\left(r_{f e r}=C_{A M P r e f} / C_{G M P r e f}\right)$. Numbers of adenine nucleotides in the poly(A) tail $\left(n_{\text {AMPtail }}\right)$ were calculated based on Equation 3 and numbers of $G$ in a sequence $\left(n_{\text {GMPref }}\right)$ :

$$
\mathrm{n}_{\text {Atail }}=\left(\frac{C_{A M P}}{C_{G M P}}-r_{\text {ref }}\right) * n_{G M P r e f}
$$

Numbers of adenine nucleotide analogs ( $\left.n_{\text {AMPXtail }}\right)$ were calculated according to Equation 4:

$$
n_{A M P X t a i l}=\frac{C_{A M P X}}{C_{G M P}} * n_{G M P r e f}
$$

\section{RNA synthesis and purification}

The sequences of RNAs used in different types of experiments are summarized in Table 1. The preparations for each RNA are described below.

\section{Short RNA (RNA A and B)}

Short RNAs were generated on a template of annealed oligonucleotides: (1) (CAGTAATACGACTCACTATAGGGGAAGCGGGC ATGCGGCCAGCCATAGCCGATCA and TGATCGGCTATGGC TGGCCGCATGCCCGCTTCCCCTATAGTGAGTCGTATTACTG) (Coleman et al. 2004), which contains the $\$ 6.5$ T7 promoter sequence (TAATACGACTCACTATA) and encodes a 35-nt long 
Downloaded from rnajournal.cshlp.org on April 26, 2023 - Published by Cold Spring Harbor Laboratory Press

mRNAs with phosphate-modified poly(A) tail

TABLE 1. RNA sequences studied in this work

\begin{tabular}{|c|c|c|c|c|}
\hline RNA name & $\begin{array}{l}\text { Length } \\
\text { (nt) }\end{array}$ & $\begin{array}{c}\text { Sequence (5' end-5' UTR-ORF-3' UTR- } \\
\text { polyA) }\end{array}$ & Preparation method & Application \\
\hline RNA A & 35 & $\begin{array}{l}\text { GAAGAAGCGGGCAUGCGGCCAGCCAUAG } \\
\text { CCGAUCA }\end{array}$ & In vitro transcription by SP6 Pol & $\begin{array}{l}\text { Analysis of incorporation efficiency of modified nucleotides } \\
\text { (Fig. 3, Fig. S1, S7) }\end{array}$ \\
\hline RNA A1 & $35+$ polyA & RNA A + polyA & $\begin{array}{l}\text { Polyadenylation of unmod } \\
\text { RNA A by PAP }\end{array}$ & $\begin{array}{l}\text { Analysis of incorporation efficiency of modified nucleotides } \\
\text { (Fig. 5, Fig. S8) }\end{array}$ \\
\hline RNA B & 35 & $\begin{array}{c}\text { GGGGAAGCGGGCAUGCGGCCAGCCAUAG } \\
\text { CCGAUCA }\end{array}$ & In vitro transcription by $\mathrm{T7} \mathrm{Pol}$ & $\begin{array}{l}\text { Analysis of incorporation efficiency of modified nucleotides } \\
\text { (Fig. 3, Fig. S1) }\end{array}$ \\
\hline RNA C & 22 & GCUCUCUCUCUAAAAAAAAAAA & Solid-phase synthesis (unmod) & Validation of LC-MS/MS method (Fig. S4) \\
\hline RNA E & 35 & $\begin{array}{l}\text { GGGGUUGCGGGCUUGCGGCCUGCCUUU } \\
\text { GCCGUUCU }\end{array}$ & $\begin{array}{l}\text { In vitro transcription by } \mathrm{T7} \mathrm{Pol} \\
\text { (unmod) }\end{array}$ & Preparation of RNA E1 (Fig. S1) \\
\hline RNA E1 & $35+$ polyA & RNA E + polyA & $\begin{array}{l}\text { Polyadenylation of unmod } \\
\text { RNA E by PAP }\end{array}$ & $\begin{array}{l}\text { Deuterated and used for verification of degradation protocol } \\
\text { (Fig. 7, Fig. S5) }\end{array}$ \\
\hline RNA F & 2105 & $\beta-S-A R C A-\left(N_{22}\right)-F F L u c-(\beta-g l o b i n)-A_{128}$ & $\begin{array}{l}\text { In vitro transcription by T7 or } \\
\text { SP6 RNA Pol (mod and unmod) }\end{array}$ & Used for translation studies in RRL (Fig. 4) \\
\hline RNA F1 & 1961 & ARCA-(N22)-FFLuc- $(\beta-\text { globin })_{2}$ & $\begin{array}{l}\text { In vitro transcription by SP6 RNA } \\
\text { Pol: NTPs as a substrate }\end{array}$ & Used as a ssRNA primer for PAP (Fig. S6) \\
\hline RNA F2 & $1961+$ polyA & RNA F1 + polyA & $\begin{array}{l}\text { Polyadenylation of RNA F1 by } \\
\text { PAP: ATP as a substrate }\end{array}$ & Analysis of unmodified polyA tail length (Fig. S6) \\
\hline RNA G & 869 & ARCA- $\left(N_{13}\right)-G L u c-(B-g l o b i n)_{2}$ & $\begin{array}{l}\text { In vitro transcription by SP6 RNA } \\
\text { Pol: NTPs as a substrate }\end{array}$ & Used as a ssRNA primer for PAP (Fig. 6, Fig. S9-S12) \\
\hline RNA G1 & $869+$ polyA & RNA G + polyA & $\begin{array}{l}\text { Polyadenylation of RNA G by } \\
\text { PAP: ATP or ATP:ATPaS D1 as } \\
\text { a substrate }\end{array}$ & $\begin{array}{l}\text { Analysis of translational properties of unmodified transcripts } \\
\text { containing ATPaS D1 in polyA tail (transfected cell lines). } \\
\text { Analysis of modified polyA tails stability towards enzymatic } \\
3^{\prime} \rightarrow 5^{\prime} \text { degradation (CNOT7 deadenylase). Analysis of } \\
\text { modified polyA tails length and composition (Fig. 6, Fig. } \\
\text { S10-S12) }\end{array}$ \\
\hline RNA H & 720 & ARCA-(N13)-GLuc-(B-globin) & $\begin{array}{l}\text { In vitro transcription by SP6 RNA } \\
\text { Pol: NTPs as a substrate }\end{array}$ & $\begin{array}{l}\text { Used as a ssRNA primer for PAP (Fig. 8, Fig. S9, S10, } \\
\text { S15-S17) }\end{array}$ \\
\hline RNA H1 & $720+$ polyA & RNA H + polyA & $\begin{array}{l}\text { Polyadenylation of RNA } \mathrm{H} \text { by } \\
\text { PAP: ATP, ATP:ATPaBH } \text { D }^{\text {1 or }} \\
\text { ATPaBH }{ }_{3} \text { D1 as a substrate }\end{array}$ & $\begin{array}{l}\text { Analysis of translational properties of unmodified transcripts } \\
\text { containing ATPaBH } 3 \text { D1 in polyA tail (transfected cell lines). } \\
\text { Analysis of modified polyA tails stability towards enzymatic } \\
3^{\prime} \rightarrow 5^{\prime} \text { degradation (CNOT7 deadenylase). Analysis of } \\
\text { modified polyA tails length and composition (Fig. 8, Fig. } \\
\text { S10, S15-S17) }\end{array}$ \\
\hline RNA I & 1001 & ARCA-(N13)-GLuc-(B-globin) $-\mathrm{A}_{128}$ & $\begin{array}{l}\text { In vitro transcription by SP6 RNA } \\
\text { Pol, NTPs }\end{array}$ & $\begin{array}{l}\text { Used as a control mRNA with template encoded polyA tail } \\
\text { for analysis of translational properties (Fig. 6, Fig. 8, Fig. } \\
\text { S9) }\end{array}$ \\
\hline
\end{tabular}

LC-MS/MS, Liquid chromatography-tandem mass spectrometry; PAP, poly(A) polymerase; NTPs, nucleoside triphosphates; ARCA, anti-reverse cap analog; RRL, rabbit reticulocyte lysate.

sequence (GGGGAAGCGGGCATGCGGCCAGCCATAGCCGA TCA); (2) (ATACGATTTAGGTGACACTATAGAAGAAGCGGGCA TGCGGCCAGCCATAGCCGATCA and TGATCGGCTATGGCT GGCCGCATGCCCGCTTCTTCTATAGTGTCACCTAAATCGTAT)
(Coleman et al. 2004), which contains the SP6 promoter sequence (CGA TTTAGG TGACAC TATA) and encodes a 35-nt long sequence (GA AGAAGC GGGCAT GCGGCC AGCCAT AGCCGA TCA). ATP analogs used for RNA preparation were synthesized, 
as previously described (Kowalska et al. 2008, 2014). A typical in vitro transcription reaction $(20 \mu \mathrm{L})$ was incubated at $37^{\circ} \mathrm{C}$ for $2 \mathrm{~h}$ and contained: RNA polymerase buffer ( $40 \mathrm{mM}$ Tris- $\mathrm{HCl} \mathrm{pH}$ 7.9, $6 \mathrm{mM} \mathrm{MgCl} 2,1 \mathrm{mM} \mathrm{DTT}$, and $2 \mathrm{mM}$ spermidine), $10 \mathrm{U} / \mu \mathrm{L}$ T7 or $1 \mathrm{U} / \mu \mathrm{L}$ SP6 RNA polymerase (Thermo Fisher Scientific), $1 \mathrm{U} / \mu \mathrm{L}$ RiboLock RNase Inhibitor (Thermo Fisher Scientific), $0.5 \mathrm{mM}$ CTP/UTP/GTP, $0.5 \mathrm{mM}$ different ATP:ATP $\alpha \mathrm{X}$ ratios, and $0.4 \mu \mathrm{M}$ annealed oligonucleotides as a template. Following a $2 \mathrm{~h}$ incubation, $1 \mathrm{U} / \mu \mathrm{L}$ DNase I (Thermo Fisher Scientific) was added and the incubation was continued for $30 \mathrm{~min}$ at $37^{\circ} \mathrm{C}$. The crude RNAs were purified using RNA Clean \& Concentrator-25 (Zymo Research). The quality of transcripts was assessed on $15 \%$ acrylamide/7 M urea gels, whereas the concentration was determined spectrophotometrically. To remove in vitro transcription sideproducts of unintended size, RNA samples were gel-purified using PAA elution buffer ( $0.3 \mathrm{M}$ sodium acetate, $1 \mathrm{mM}$ ethylenediaminetetraacetic acid [EDTA], and $0.05 \%$ Triton X-100), precipitated with isopropanol, and dissolved in water.

\section{Short RNA without an A in the sequence (RNA E)}

Short RNAs were generated on a template of annealed oligonucleotides (the same sequence as RNA B but with $U$ instead of $A$ ) (CAGTAATACGACTCACTATAGGGGTTGCGGGCTTGCGGCCT GCCTTTGCCGTTCT and AGAACGGCAAAGGCAGGCCGCAA GCCCGCAACCCCTATAGTGAGTCGTATTACTG), which contained the T7 promoter sequence (TAATACGACTCACTATA) and encoded a 35-nt long sequence (GGGGTTGCGGGCTT GCGGCCTGCCTTTGCCGTTCT). The in vitro transcription reaction $(200 \mu \mathrm{L})$ was incubated at $37^{\circ} \mathrm{C}$ for $3 \mathrm{~h}$ and contained: RNA polymerase buffer $(40 \mathrm{mM}$ Tris- $\mathrm{HCl} \mathrm{pH} 7.9,20 \mathrm{mM} \mathrm{MgCl}$, $1 \mathrm{mM}$ DTT, and $2 \mathrm{mM}$ spermidine), $10 \mathrm{U} / \mu \mathrm{L}$ T7 RNA polymerase (Thermo Fisher Scientific), $1 \mathrm{U} / \mu \mathrm{L}$ RiboLock RNase Inhibitor (Thermo Fisher Scientific), $5 \mathrm{mM}$ CTP/UTP/GTP, and $1 \mu \mathrm{M}$ annealed oligonucleotides as a template. Following $3 \mathrm{~h}$ incubation, $1 \mathrm{U} / \mu \mathrm{L}$ DNase I (Thermo Fisher Scientific) was added and the incubation was continued for $30 \mathrm{~min}$ at $37^{\circ} \mathrm{C}$. IVT products were extracted using phenol-chloroform and purified using HPLC on a Clarity $3 \mu \mathrm{m}$ Oligo-RP C18 column (Phenomenex). To elute the desired products, two eluents were used: Eluent A: $50 \mathrm{mM}$ TEA and Eluent $B: 75 \%$ acetonitrile in the following gradient: 0-5 min 95\% A, 5-20 min 87.5\% A, 20-21 min 50\% A using a $1 \mathrm{~mL} / \mathrm{min}$ flow rate. Obtained products were used to obtain short RNAs with a poly(A) tail (RNA E1), as described below.

\section{Short RNA with the poly(A) (RNA A1 and E1)}

Short RNAs with a poly(A) tail were generated in a polyadenylation reaction. A typical reaction mixture $(20 \mu \mathrm{L})$ was incubated at $37^{\circ} \mathrm{C}$ for $1 \mathrm{~h}$ and contained $1 \mu \mathrm{g} 35 \mathrm{nt}$ RNA fragment, $1 \mathrm{mM}$ different ATP([D]ATP):ATP $\alpha X$ ratios, $1 \mathrm{U} / \mu \mathrm{L}$ RiboLock RNase Inhibitor (Thermo Fisher Scientific), and PAP dedicated buffer and PAP (Lucigen) from 0.05 to $0.2 \mathrm{U} / \mu \mathrm{L}$ reaction. The RNAs were purified using RNA Clean \& Concentrator-25 (Zymo Research). The quality of transcripts was assessed on $2 \%$ agarose gels, whereas the concentration was determined spectrophotometrically.

\section{Firefly luciferase (RNA F and F1)}

For studies of transcription and translation efficiency of mRNA uniformly modified with phosphorothioate, Firefly luciferase tran- scripts (RNA F) were prepared based on the PJET_T7_ FFLuc_128A and pJET_SP6_FFLuc_128A plasmids (Warminski et al. 2017). The DNA template was purified with GeneJET Plasmid Midiprep Kit (Thermo Fisher Scientific) and linearized with the Aarl restriction enzyme (Thermo Fisher Scientific). The restriction site for Aarl was located downstream from the poly(A) tract; therefore, IVT RNA F contained a template-encoded poly (A) tail. The completeness of plasmid linearization was evaluated by $1 \% 1 \times$ Tris-boric acid-EDTA (TBE) agarose gel electrophoresis, the sample was purified with QIAquick PCR Purification Kit (Qiagen) and used as a DNA template for in vitro transcription. The in vitro transcription reaction $\operatorname{mix}(30 \mu \mathrm{L})$ was maintained for $4 \mathrm{~h}$ at $40^{\circ} \mathrm{C}$ and contained transcription buffer $(40 \mathrm{mM}$ Tris- $\mathrm{HCl}$ $\mathrm{pH} 7.9,10 \mathrm{mM} \mathrm{MgCl} 2,1 \mathrm{mM}$ DTT, and $2 \mathrm{mM}$ spermidine), 0.33 $\mathrm{U} / \mu \mathrm{L}$ SP6 or T7 RNA polymerase, $0.66 \mathrm{U} / \mu \mathrm{L}$ RiboLock RNase inhibitor, $0.5 \mathrm{mM}$ ATP or $0.5 \mathrm{mM}$ mixture of ATP and ATP $\alpha$ S D1, $0.5 \mathrm{mM}$ CTP and UTP, $0.125 \mathrm{mM}$ GTP, $1.25 \mathrm{mM} \beta$-S-ARCA (Kuhn et al. 2010) as a cap analog, and 120 ng of linearized plasmid. In vitro transcription was followed by removal of the DNA template with DNase I ( 30 min incubation at $37^{\circ} \mathrm{C}$ with $0.06 \mathrm{U} / \mu \mathrm{L}$ of the enzyme), and purification with NucleoSpin RNA Clean-up XS (MachereyNagel). The quality of mRNA was analyzed using $1 \% 1 \times$ TBE agarose gel electrophoresis, and the concentration was determined spectrophotometrically (NanoDrop 2000c).

\section{Gaussia luciferase (RNA $G, H$, and I)}

For analysis of poly(A) tail composition, length, stability, and translational properties, three types of mRNA encoding Gaussia luciferase were prepared, differing in the number of $H$. sapiens $\beta$ globin $3^{\prime}$ UTR sequences and the presence or absence of a poly (A) tail: RNA I with a double 3' UTR and template encoding a poly(A) tail, and RNA $H$ and RNA G without poly(A) tails, and with single or double $3^{\prime}$ UTR sequences, respectively. The pJET_SP6_GLuc_128A plasmid (Warminski et al. 2017), purified with the GeneJET Plasmid Midiprep Kit (Thermo Fisher Scientific), was used as a DNA template for a polymerase chain reaction (PCR) performed using Phusion High-Fidelity DNA polymerase (Thermo Fisher Scientific). Two amplification strategies were involved to obtain the template lacking an encoded poly (A) sequence (RNA G and $H$ ), and therefore suitable for further polyadenylation of IVT mRNA. The DNA template for in vitro transcription of RNA H was amplified using the SP6_Gluc_For_II (5'GTCCCAATTAGTAGCATCACGCTGTG-3') and PJET_Luc_FL_ UTR_REV (5'-GCAATGAAAATAAATGTTTTTTATTAGGCAGAA TCCAAATGC-3') primers and was purified with the QIAquick PCR Purification Kit (Qiagen) directly after the PCR reaction. For preparation of the DNA template for in vitro transcription of RNA G and RNA I, the SP6_Gluc_For_II (5'-GTCCCAATTAGTA GCATCACGCTGTG-3') and pJET_SQ_rev_II (5'-GCCAAGAAA ACCCACGCCACCTAC-3') primers were used. For the amplified DNA template, an additional step of restriction digestion was necessary to remove the sequence downstream from the second $3^{\prime}$ UTR (for in vitro transcription of RNA G) or downstream from the poly $(A)$ coding region (for in vitro transcription of RNA I). To obtain highly concentrated DNA for more efficient restriction digestion, the amplification product was extracted from the PCR reaction mixture with phenol:chloroform $(1: 1, v / v)$ and precipitated with 1.25 M ammonium acetate and isopropanol at RT, followed by a washing step with $70 \%$ ethanol. The precipitated 
DNA pellet was resuspended in 20-50 $\mu \mathrm{L}$ RNase/DNase free water (Sigma). To obtain the DNA template for in vitro transcription of RNA G, restriction digestion using Mssl (Pmel) (Thermo Fisher Scientific) was performed, resulting in blunt-ended doublestranded DNA (dsDNA) containing a double 3' UTR sequence and lacking a poly(A) tail. To prepare the DNA template for in vitro transcription of RNA I, the Aarl (Thermo Fisher Scientific) restriction enzyme was used. The restriction digestion efficiency was validated using 1\% $1 \times$ TBE agarose gel electrophoresis and purified with a QIAquick PCR Purification Kit (Qiagen).

A typical in vitro transcription reaction mixture $(30-40 \mu \mathrm{L})$ was incubated for $4 \mathrm{~h}$ at $40^{\circ} \mathrm{C}$ and contained: transcription buffer (40 mM Tris- $\mathrm{HCl} \mathrm{pH} \mathrm{7.9,} 10 \mathrm{mM} \mathrm{MgCl} 2,1 \mathrm{mM} \mathrm{DTT}$, and $2 \mathrm{mM}$ spermidine), $2.5 \mathrm{U} / \mu \mathrm{L}$ SP6 RNA polymerase (a second $2.5 \mathrm{U} / \mu \mathrm{L}$ was added after $2 \mathrm{~h}$ of incubation), $2 \mathrm{U} / \mu \mathrm{L}$ RiboLock RNase inhibitor, $2 \mathrm{mM}$ ATP, CTP and UTP, $0.25 \mathrm{mM}$ GTP, $2.5 \mathrm{mM}$ ARCA, and $250 \mathrm{ng} / \mu \mathrm{L}$ DNA template. In vitro transcription was followed by removal of the DNA template with DNase I (30 min incubation at $37^{\circ} \mathrm{C}$ with $0.1 \mathrm{U} / \mu \mathrm{L}$ of the enzyme). The crude transcript was initially purified with NucleoSpin RNA Clean-up XS (MachereyNagel), followed by a second purification step using RP HPLC. To isolate the homogenous mRNA fraction sufficient for further polyadenylation, obtained transcripts were purified on an Agilent Technologies Series 1200 HPLC using RNASep Prep (ADS Biotec) at $55^{\circ} \mathrm{C}$, as described previously (Weissman et al. 2012). For mRNA purification, a linear gradient of buffer $B$ (0.1 M triethylammonium acetate $\mathrm{pH} 7.0$ and $25 \%$ acetonitrile) from $40 \%$ to $60 \%$ in buffer $\mathrm{A}(0.1 \mathrm{M}$ triethylammonium acetate $\mathrm{pH} 7.0$ ) over $25 \mathrm{~min}$ at $0.9 \mathrm{~mL} / \mathrm{min}$ was applied. mRNA from collected fractions was recovered by precipitation with $0.3 \mathrm{M}$ sodium acetate $\mathrm{pH} 5.2$ and isopropanol at RT, followed by a washing step with $70 \%$ ethanol. The purity of mRNA was analyzed using $1 \% 1 \times$ TBE agarose gel electrophoresis and selected fractions were combined. The absorbance of the mRNA sample was measured spectrophotometrically (NanoDrop 2000c) and the concentration was determined using the extinction coefficient predicted for a particular mRNA sequence by DNA Calculator (software available on www.molbiotools.com).

\section{mRNA polyadenylation by PAP (RNA G1 and H1)}

The $3^{\prime}$ ends of Gaussia luciferase encoding transcripts were tailed with a poly $(A)$ sequence using an enzymatic approach with $E$. coli PAP (Lucigen). The PAP reaction mixture $(5-10 \mu \mathrm{L})$ was incubated at $37^{\circ} \mathrm{C}$ for $45 \mathrm{~min}$ (for the preparation of RNA G1 with phosphorothioate-modified poly(A)), while the preparation of the RNA H1 reaction mixture was incubated for $10 \mathrm{~min}$ (for ATP and ATP: $A T P \alpha B H_{3}$ D1 49:1, 24:1, and 14:1), 12 min (for ATP:ATP $\alpha B H_{3}$ D1 9:1), $15 \mathrm{~min}$ (for ATP:ATP $\alpha B H_{3}$ D1 5:1), $17 \mathrm{~min}$ (for ATP: $A T P \alpha B H_{3}$ D1 3:1), or 45 min (for ATP:ATP $\alpha B H_{3}$ D1 1:1 and $\mathrm{ATP} \alpha \mathrm{BH}_{3} \mathrm{D} 1$ only). The reaction mixture contained PAP buffer (50 mM Tris- $\mathrm{HCl} \mathrm{pH} 8.0,250 \mathrm{mM} \mathrm{NaCl}$, and $10 \mathrm{mM} \mathrm{MgCl}_{2}$ ), 0.2 $\mathrm{U} / \mu \mathrm{L}$ PAP enzyme, $10 \mathrm{U}$ Ribolock RNase inhibitor, $0.5 \mu \mathrm{M}$ RNA $\mathrm{G}$ or $0.2 \mu \mathrm{M}$ RNA $H, A T P$, or a mixture of ATP and ATP $\alpha$ S D1 or ATP and ATP $\alpha B H_{3}$ D1 at a total concentration of $0.25 \mathrm{mM}$; the reaction was stopped by the addition of EDTA to a final concentration of $25 \mathrm{mM}$. Polyadenylated mRNA was extracted with phenol: chloroform (1:1, v/v) and precipitated with 1.25 M ammonium acetate and isopropanol at RT, followed by a washing step with $70 \%$ ethanol. Polyadenylated mRNA pellets were resuspended in 10 $\mu \mathrm{L}$ of RNase/DNase free water (Sigma). The absorbance of the mRNA sample was measured spectrophotometrically (NanoDrop 2000c), and the concentration was determined using an extinction coefficient predicted for a particular mRNA sequence by DNA Calculator (software available on www .molbiotools.com). To assess the length of $\operatorname{poly}(A)$ tails, polyadenylated mRNAs were electrophoretically resolved in a 1\% 1× TBE agarose gel between two RNA ladders (RiboRuler High Range, Thermo Fisher Scientific) and analyzed using Image Lab Software 6.0.1 (Bio-Rad). Bands were automatically detected and the length of mRNAs was calculated using semi-logarithmic analysis with reference to the two RiboRuler RNA ladders. The poly(A) tail length was estimated as the difference between the length of the polyadenylated mRNA and the transcript without a poly(A) tail, used as a primer for PAP.

\section{Poly(A) tail degradation assay (RNA G1 and H1)}

The stability of poly(A) tails modified with phosphorothioate (RNA G1) or boranophosphate (RNA H1) was examined by subjecting mRNAs to deadenylation using recombinant CNOT7 deadenylase (Mathys et al. 2014). A single experiment was performed as a set of simultaneous reactions for mRNAs polyadenylated by PAP and the mixture of ATP and phospho-modified analog as a substrate (e.g., ATP:ATP $\alpha$ S D1 marked as 9:1, 4:1, 3:1, 2:1, and 1:1). RNA G1 or $\mathrm{H} 1$ with an unmodified poly(A) tail (marked as 10:0) served as a positive control. Each degradation assay was performed as a single-tube reaction, containing CNOT7 buffer (10 mM Tris- $\mathrm{HCl} \mathrm{pH} \mathrm{8.0,50} \mathrm{mM} \mathrm{KCl,} 5 \mathrm{mM} \mathrm{MgCl}$, and $10 \mathrm{mM}$ DTT), polyadenylated mRNA (12 ng/ $\mu \mathrm{L})$, and CNOT7 deadenylase $(0.2 \mu \mathrm{g} / \mu \mathrm{L})$. After $0,20,40,60$, or $120 \mathrm{~min}$ of incubation at $37^{\circ} \mathrm{C}, 2.5 \mu \mathrm{L}$ of the reaction mixture was collected and the CNOT7 deadenylase was inactivated by addition of an equal volume of loading dye (95\% formamide, 50 mM EDTA, 0.025\% SDS, $0.025 \%$ bromophenol blue, $0.025 \%$ xylene cyanol, and $0.025 \%$ ethidium bromide). Products of the degradation were analyzed by $1 \% 1 \times$ TBE agarose gel electrophoresis. Using Image Lab Software 6.0.1 (Bio-Rad), the degradation rate was estimated as the difference of the mRNA length before deadenylation and its length at a particular time point.

\section{In vitro translation with RRL lysate (RNA F)}

The RRL (Promega) was used to determine the influence of internal modifications on translation efficiency of RNA $F$. The reaction mixture $(9 \mu \mathrm{L})$ contained reticulocyte lysate $(4 \mu \mathrm{L})$, amino acid mixture without leucine $(0.2 \mu \mathrm{L}, 1 \mathrm{mM}$ solution; the final concentration in $10 \mu \mathrm{L}$ reaction mix was $20 \mu \mathrm{M}$ ), amino acid mixture without methionine $(0.2 \mu \mathrm{L}, 1 \mathrm{mM}$ solution; the final concentration in $10 \mu \mathrm{L}$ reaction mix was $20 \mu \mathrm{M})$, potassium acetate $(1.9 \mu \mathrm{L}$ of $1 \mathrm{M}$ solution), and $\mathrm{MgCl}_{2}(0.4 \mu \mathrm{L}$ of $25 \mathrm{mM}$ solution). After $1 \mathrm{~h}$ of incubation at $30^{\circ} \mathrm{C}, 1 \mu \mathrm{L}$ of the appropriate RNA F dilution $(3.0 \mathrm{ng} / \mu \mathrm{L}$, $1.5 \mathrm{ng} / \mu \mathrm{L}, 0.75 \mathrm{ng} / \mu \mathrm{L}$, or $0.375 \mathrm{ng} / \mu \mathrm{L}$ ) was added and the incubation of the reaction mixture was continued at $30^{\circ} \mathrm{C}$ for $1 \mathrm{~h}$. The reaction was stopped by freezing in liquid nitrogen. To detect luminescence from Firefly luciferase, $50 \mu \mathrm{L}$ Luciferase Assay Reagent (tricine, $\mathrm{Mg}\left(\mathrm{HCO}_{3}\right)_{2}, \mathrm{MgSO}_{4}, 0.1 \mathrm{mM}$ EDTA, DTT, ATP, luciferin [VivoGlo Luciferin, In Vivo Grade; Promega], and coenzyme A) was added to the sample and the luminescence was 
measured on a Synergy H1 (BioTek) microplate reader. The results are presented as proportions between the regression coefficients of the linear relationships between the RNA $F$ concentration in the translation reaction $(0.3 \mathrm{ng} / \mu \mathrm{L}, 0.15 \mathrm{ng} / \mu \mathrm{L}$, $0.075 \mathrm{ng} / \mu \mathrm{L}$, or $0.0375 \mathrm{ng} / \mu \mathrm{L}$ ) and the corresponding luminescence signal. The relative luciferase activity was normalized to the values obtained with unmodified RNA $F$, calculated as mean values from three independent experiments \pm standard deviation (SD).

\section{Protein expression studies (RNA G, G1, H, H1, and I)}

The murine immature dendritic cell line JAWS II (American Type Culture Collection [ATCC] CRL-11904) was grown in RPMI 1640 medium (Gibco) supplemented with $10 \%$ fetal bovine serum (FBS), sodium pyruvate (Gibco), 1\% penicillin/streptomycin, and $5 \mathrm{ng} / \mathrm{mL}$ granulocyte-macrophage colony-stimulating factor (PeproTech) at $5 \% \mathrm{CO}_{2}$ and $37^{\circ} \mathrm{C}$. HeLa (human cervical epithelial carcinoma, ATCC CCL-2) cells were grown in DMEM (Gibco) supplemented with 10\% FBS (Sigma), GlutaMAX (Gibco), and 1\% penicillin/streptomycin (Gibco) at $5 \% \mathrm{CO}_{2}$ and $37^{\circ} \mathrm{C}$. For all experiments, the passage number of studied cells was between 5 and 25 . In a typical experiment, $10^{4}$ per well JAWS II cells were seeded into a 96-well plate on the day of the experiment in 100 $\mu \mathrm{L}$ medium without antibiotics. In the case of the HeLa cell line, $4 \times 10^{3} \mathrm{HeLa}$ cells per well were seeded $24 \mathrm{~h}$ before transfection into a 96-well plate in $100 \mu \mathrm{L}$ medium without antibiotics. Cells in each well were transfected for $16 \mathrm{~h}$ using a mixture of $0.3 \mu \mathrm{L}$ Lipofectamine MessengerMAX Transfection Reagent (Invitrogen) and 25 ng mRNA in $10 \mu \mathrm{L}$ Opti-MEM (Gibco). To assess Gaussia luciferase expression at multiple time points, the medium was fully removed and replaced with fresh media after 16, 40, 64, and 88 h. To detect luminescence from Gaussia luciferase, $50 \mu \mathrm{L} 10 \mathrm{ng} /$ $\mathrm{mL}$ h-coelenterazine (NanoLight) in PBS was added to $10 \mu \mathrm{L}$ cell culture medium and the luminescence was measured on a Synergy H1 (BioTek) microplate reader. Total protein expression (cumulative luminescence) for each mRNA over $4 \mathrm{~d}$ was reported as a mean value \pm SD normalized to RNA I with a template-encoded $A_{128} \operatorname{poly}(A)$ tail.

\section{SUPPLEMENTAL MATERIAL}

Supplemental material is available for this article.

\section{ACKNOWLEDGMENTS}

We thank Mariusz Czarnocki-Cieciura (International Institute of Molecular and Cell Biology, Warsaw) for providing purified recombinant human CNOT7 deadenylase. This work was supported by the National Science Centre, Poland (UMO-2016/23/N/ ST4/03186 to D.S., UMO-2016/21/B/ST5/02556 to J.J.).

Author contributions: D.S., M.S., J.K., and J.J. designed the study. D.S. synthesized nucleotides used in the work, obtained and analyzed RNAs $A, A 1, B, E$, and E1, and performed all MS experiments. M.S. obtained RNAs F, F1, F2, G, G1, H, H1, and I and performed poly(A) tail degradation assays (RNA G1, H1). P.J.S. performed protein expression studies in cultured cells (RNA G, G1, H, H1, I). M.W. obtained RNA C. D.S., M.S., J.K., and J.J. wrote the first draft of the manuscript. All authors approve the final version of the manuscript.

Received July 2, 2020; accepted August 13, 2020.

\section{REFERENCES}

Anderson BR, Muramatsu H, Nallagatla SR, Bevilacqua PC, Sansing LH, Weissman D, Kariko K. 2010. Incorporation of pseudouridine into mRNA enhances translation by diminishing PKR activation. Nucleic Acids Res 38: 5884-5892. doi:10.1093/nar/ gkq347

Anhauser L, Huwel S, Zobel T, Rentmeister A. 2019. Multiple covalent fluorescence labeling of eukaryotic mRNA at the poly(A) tail enhances translation and can be performed in living cells. Nucleic Acids Res 47: e42. doi:10.1093/nar/gkz084

Armstrong WW, Yee D, Eckstein F. 1979. Mechanistic studies on deoxyribonucleic-acid dependent ribonucleic-acid polymerase from Escherichia coli using phosphorothioate analogs. 2. Elongation reaction. Biochemistry 18: 4120-4123. doi:10.1021/ bi00586a010

Astrom J, Astrom A, Virtanen A. 1991. Invitro deadenylation of mammalian messenger-RNA by a HELA-cell 3' exonuclease. EMBO J 10: 3067-3071. doi:10.1002/j.1460-2075.1991.tb07858.x

Auriola S, Frith J, Rogers MJ, Koivuniemi A, Monkkonen J. 1997. Identification of adenine nucleotide-containing metabolites of bisphosphonate drugs using ion-pair liquid chromatography-electrospray mass spectrometry. J Chromatogr B 704: 187-195. doi:10 .1016/S0378-4347(97)00490-8

Balbo PB, Bohm A. 2007. Mechanism of poly(A) polymerase: structure of the enzyme-MgATP-RNA ternary complex and kinetic analysis. Structure 15: 1117-1131. doi:10.1016/j.str.2007.07.010

Benteyn D, Anguille S, Van Lint S, Heirman C, Van Nuffel AMT, Corthals J, Ochsenreither S, Waelput W, Van Beneden K, Breckpot K, et al. 2013. Design of an optimized Wilms' Tumor 1 (WT1) mRNA construct for enhanced WT1 expression and improved immunogenicity in vitro and in vivo. Mol Ther Nucleic Acids 2: e134. doi:10.1038/mtna.2013.54

Bernstein P, Peltz SW, Ross J. 1989. The poly(A)-poly(A)-binding protein complex is a major determinant of messenger-RNA stability in vitro. Mol Cell Biol 9: 659-670. doi:10.1128/MCB.9.2.659

Beverly M, Hagen C, Slack O. 2018. Poly A tail length analysis of in vitro transcribed mRNA by LC-MS. Anal Bioanal Chem 410: 16671677. doi:10.1007/s00216-017-0840-6

Bianchin C, Mauxion F, Sentis S, Seraphin B, Corbo L. 2005. Conservation of the deadenylase activity of proteins of the Caf1 family in human. RNA 11: 487-494. doi:10.1261/rna.7135305

Borman AM, Michel YM, Kean KM. 2000. Biochemical characterisation of cap-poly(A) synergy in rabbit reticulocyte lysates: the elF4G-PABP interaction increases the functional affinity of elF4E for the capped mRNA 5'-end. Nucleic Acids Res 28: 4068-4075. doi:10.1093/nar/28.21.4068

Brawerman G. 1981. The role of the poly(A) sequence in mammalian messenger-RNA. Crit Rev Biochem 10: 1-38. doi:10.3109/ 10409238109114634

Burgers PMJ, Eckstein F. 1978. Absolute-configuration of diastereomers of adenosine $5^{\prime}$-O-(1-thiotriphosphate): consequences for stereochemistry of polymerization by DNA-dependent RNA-polymerase from Escherichia coli. Proc Natl Acad Sci 75: 4798-4800. doi:10.1073/pnas.75.10.4798

Calderisi G, Glasner H, Breuker K. 2020. Radical transfer dissociation for de novo characterization of modified ribonucleic acids by mass spectrometry. Angew Chem Int Ed Engl 59: 4309-4313. doi:10 .1002/anie.201914275 
Chang H, Lim J, Ha M, Kim VN. 2014. TAIL-seq: genome-wide determination of poly $(A)$ tail length and $3^{\prime}$ end modifications. Mol Cell 53: 1044-1052. doi:10.1016/j.molcel.2014.02.007

Chen CYA, Shyu AB. 2011. Mechanisms of deadenylation-dependent decay. Wiley Interdiscip Rev RNA 2: 167-183. doi:10.1002/wrna .40

Coleman TM, Wang GC, Huang FQ. 2004. Superior 5 ' homogeneity of RNA from ATP-initiated transcription under the T7 $\phi 2.5$ promoter. Nucleic Acids Res 32: e14. doi:10.1093/nar/gnh007

Coller JM, Gray NK, Wickens MP. 1998. mRNA stabilization by poly(A) binding protein is independent of poly $(\mathrm{A})$ and requires translation. Genes Dev 12: 3226-3235. doi:10.1101/gad.12.20.3226

Decker CJ, Parker R. 1993. A turnover pathway for both stable and unstable messenger-RNAs in yeast: evidence for a requirement for deadenylation. Genes Dev 7: 1632-1643. doi:10.1101/gad.7.8 .1632

Deo RC, Bonanno JB, Sonenberg N, Burley SK. 1999. Recognition of polyadenylate RNA by the poly(A)-binding protein. Cell 98: 835845. doi:10.1016/S0092-8674(00)81517-2

Dodson RE, Shapiro DJ. 2002. Regulation of pathways of mRNA destabilization and stabilization. Prog Nucleic Acid Res Mol Biol 72: 129-164. doi:10.1016/S0079-6603(02)72069-2

Eckmann CR, Rammelt C, Wahle E. 2011. Control of poly(A) tail length. Wiley Interdiscip Rev RNA 2: 348-361. doi:10.1002/ wrna. 56

Eckstein F. 2014. Phosphorothioates, essential components of therapeutic oligonucleotides. Nucleic Acid Ther 24: 374-387. doi:10 .1089/nat.2014.0506

Eckstein F, Thomson JB. 1995. Phosphate analogs for study of DNA polymerases. Methods Enzymol 262: 189-202. doi:10.1016/ 0076-6879(95)62018-4

Eckstein F, Armstrong VW, Sternbach H. 1976. Stereochemistry of polymerization by DNA-dependent RNA-polymerase from Escherichia coli: investigation with a diastereomeric ATP analog. Proc Natl Acad Sci 73: 2987-2990. doi:10.1073/pnas.73.9.2987

Gallie DR. 1991. The cap and poly(A) tail function synergistically to regulate messenger RNA translational efficiency. Genes Dev 5: 2108-2116. doi:10.1101/gad.5.11.2108

Gaur RK, Krupp G. 1993. Enzymatic RNA synthesis with deoxynucleoside 5'-O-(1-thiotriphosphates). FEBS Lett 315: 56-60. doi:10 .1016/0014-5793(93)81132-J

Geisberg JV, Moqtaderi Z, Fan XC, Ozsolak F, Struhl K. 2014. Global analysis of mRNA isoform half-lives reveals stabilizing and destabilizing elements in yeast. Cell 156: 812-824. doi:10.1016/j.cell .2013.12.026

Gish G, Eckstein F. 1988. DNA and RNA sequence determination based on phosphorothioate chemistry. Science 240: 1520-1522. doi:10.1126/science. 2453926

Gong LZ, McCullagh JSO. 2014. Comparing ion-pairing reagents and sample dissolution solvents for ion-pairing reversed-phase liquid chromatography/electrospray ionization mass spectrometry analysis of oligonucleotides. Rapid Commun Mass Spectrom 28: 339350. doi:10.1002/rcm.6773

Goss DJ, Kleiman FE. 2013. Poly(A) binding proteins: are they all created equal? Wiley Interdiscip Rev RNA 4: 167-179. doi:10.1002/ wrna.1151

Griffiths AD, Potter BVL, Eperon IC. 1987. Stereospecificity of nucleases towards phosphorothioate-substituted RNA: stereochemistry of transcription by T7 RNA polymerase. Nucleic Acids Res 15: 4145-4162. doi:10.1093/nar/15.10.4145

Grudzien-Nogalska E, Kiledjian M. 2017. New insights into decapping enzymes and selective mRNA decay. Wiley Interdiscip Rev RNA 8: 1-11. doi:10.1002/wrna.1379

Grudzien-Nogalska E, Jemielity J, Kowalska J, Darzynkiewicz E, Rhoads RE. 2007. Phosphorothioate cap analogs stabilize mRNA and increase translational efficiency in mammalian cells. RNA 13: 1745-1755. doi:10.1261/rna.701307

Hall AHS, Wan J, Shaughnessy EE, Shaw BR, Alexander KA. 2004. RNA interference using boranophosphate siRNAs: structure-activity relationships. Nucleic Acids Res 32: 5991-6000. doi:10.1093/ nar/gkh936

Holtkamp S, Kreiter S, Selmi A, Simon P, Koslowski M, Huber C, Tureci O, Sahin U. 2006. Modification of antigen-encoding RNA increases stability, translational efficacy, and T-cell stimulatory capacity of dendritic cells. Blood 108: 4009-4017. doi:10.1182/ blood-2006-04-015024

Jaffe EK, Cohn M. 1978. Divalent cation-dependent stereospecificity of adenosine 5'-O-(2-thiotriphosphate) in hexokinase and pyruvate-kinase reactions: absolute stereochemistry of diastereoisomers of adenosine 5'-O-(2-thiotriphosphate). J Biol Chem 253: 4823-4825.

Jalkanen AL, Coleman SJ, Wilusz J. 2014. Determinants and implications of mRNA poly(A) tail size: does this protein make my tail look big? Semin Cell Dev Biol 34: 24-32. doi:10.1016/j.semcdb.2014 .05 .018

Jemielity J, Kowalska J, Rydzik AM, Darzynkiewicz E. 2010. Synthetic mRNA cap analogs with a modified triphosphate bridge: synthesis, applications and prospects. New J Chem 34: 829-844. doi:10.1039/c0nj00041h

Kariko K. 2019. In vitro-transcribed mRNA therapeutics: out of the shadows and into the spotlight. Mol Ther 27: 691-692. doi:10 .1016/j.ymthe.2019.03.009

Kariko K, Muramatsu H, Welsh FA, Ludwig J, Kato H, Akira S, Weissman D. 2008. Incorporation of pseudouridine into mRNA yields superior nonimmunogenic vector with increased translational capacity and biological stability. Mol Ther 16: 1833-1840. doi:10.1038/mt.2008.200

Kariko K, Muramatsu H, Ludwig J, Weissman D. 2011. Generating the optimal mRNA for therapy: HPLC purification eliminates immune activation and improves translation of nucleoside-modified, protein-encoding mRNA. Nucleic Acids Res 39: e142. doi:10.1093/ nar/gkr695

Kariko K, Muramatsu H, Keller JM, Weissman D. 2012. Increased erythropoiesis in mice injected with submicrogram quantities of pseudouridine-containing mRNA encoding erythropoietin. Mol Ther 20: 948-953. doi:10.1038/mt.2012.7

Kawaguchi D, Kodama A, Abe N, Takebuchi K, Hashiya F, Tomoike F, Nakamoto K, Kimura Y, Shimizu Y, Abe H. 2020. Phosphorothioate modification of mRNA accelerates the rate of translation initiation to provide more efficient protein synthesis. Angew Chem doi:10 .1002/anie.202007111

Kowalak JA, Pomerantz SC, Crain PF, McCloskey JA. 1993. A novel method for the determination of posttranscriptional modification in RNA by mass-spectrometry. Nucleic Acids Res 21: 45774585. doi:10.1093/nar/21.19.4577

Kowalska J, Lewdorowicz M, Darzynkiewicz E, Jemielity J. 2007. A simple and rapid synthesis of nucleotide analogues containing a phosphorothioate moiety at the terminal position of the phosphate chain. Tetrahedron Lett 48: 5475-5479. doi:10.1016/j .tetlet.2007.05.170

Kowalska J, Lewdorowicz M, Zuberek J, Grudzien-Nogalska E, Bojarska E, Stepinski J, Rhoads RE, Darzynkiewicz E, Davis RE, Jemielity J. 2008. Synthesis and characterization of mRNA cap analogs containing phosphorothioate substitutions that bind tightly to elF4E and are resistant to the decapping pyrophosphatase DcpS. RNA 14: 1119-1131. doi:10.1261/rna.990208

Kowalska J, Wypijewska del Nogal A, Darzynkiewicz ZM, Buck J, Nicola C, Kuhn AN, Lukaszewicz M, Zuberek J, Strenkowska M, Ziemniak M, et al. 2014. Synthesis, properties, and biological activity of boranophosphate analogs of the mRNA cap: versatile 
tools for manipulation of therapeutically relevant cap-dependent processes. Nucleic Acids Res 42: 10245-10264. doi:10.1093/ nar/gku757

Kozak M. 2005. Regulation of translation via mRNA structure in prokaryotes and eukaryotes. Gene 361: 13-37. doi:10.1016/j.gene .2005.06.037

Kuhn AN, Diken M, Kreiter S, Selmi A, Kowalska J, Jemielity J, Darzynkiewicz E, Huber C, Tureci O, Sahin U. 2010. Phosphorothioate cap analogs increase stability and translational efficiency of RNA vaccines in immature dendritic cells and induce superior immune responses in vivo. Gene Ther 17: 961-971. doi:10.1038/gt.2010.52

Legnini I, Alles J, Karaiskos N, Ayoub S, Rajewsky N. 2019. FLAM-seq: full-length mRNA sequencing reveals principles of poly(A) tail length control. Nat Methods 16: 879-886. doi:10.1038/s41592019-0503-y

Lima SA, Chipman LB, Nicholson AL, Chen YH, Yee BA, Yeo GW, Coller J, Pasquinelli AE. 2017. Short poly(A) tails are a conserved feature of highly expressed genes. Nat Struct Mol Biol 24: 10571063. doi:10.1038/nsmb.3499

Lin LN, Caton-Williams J, Kaur M, Patino AM, Sheng J, Punetha J, Huang Z. 2011. Facile synthesis of nucleoside $5^{\prime}$-( $\alpha$-P-seleno)-triphosphates and phosphoroselenoate RNA transcription. RNA 17: 1932-1938. doi:10.1261/rna.2719311

Liu YS, Nie H, Liu HX, Lu FL. 2019. Poly(A) inclusive RNA isoform sequencing (PAlso-seq) reveals wide-spread non-adenosine residues within RNA poly(A) tails. Nat Commun 10: 5292. doi:10 .1038/s41467-019-13228-9

Lobue PA, Jora M, Addepalli B, Limbach PA. 2019. Oligonucleotide analysis by hydrophilic interaction liquid chromatography-mass spectrometry in the absence of ion-pair reagents. J Chromatogr A 1595: 39-48. doi:10.1016/j.chroma.2019.02.016

Mangus DA, Evans MC, Jacobson A. 2003. Poly(A)-binding proteins: multifunctional scaffolds for the post-transcriptional control of gene expression. Genome Biol 4: 223. doi:10.1186/gb-2003-47-223

Marzluff WF, Wagner EJ, Duronio RJ. 2008. Metabolism and regulation of canonical histone mRNAs: life without a poly(A) tail. Nat Rev Genet 9: 843-854. doi:10.1038/nrg2438

Mathys $H$, Basquin J, Ozgur S, Czarnocki-Cieciura M, Bonneau F, Aartse A, Dziembowski A, Nowotny M, Conti E, Filipowicz W. 2014. Structural and biochemical insights to the role of the CCR4-NOT complex and DDX6 ATPase in microRNA repression. Mol Cell 54: 751-765. doi:10.1016/j.molcel.2014.03.036

Miller JE, Reese JC. 2012. Ccr4-Not complex: the control freak of eukaryotic cells. Crit Rev Biochem Mol Biol 47: 315-333. doi:10 .3109/10409238.2012.667214

Muddiman DC, Cheng XH, Udseth HR, Smith RD. 1996. Charge-state reduction with improved signal intensity of oligonucleotides in electrospray ionization mass spectrometry. J Am Soc Mass Spectrom 7: 697-706. doi:10.1016/1044-0305(96)80516-2

Murray EL, Schoenberg DR. 2008. Assays for determining poly(A) tail length and the polarity of mRNA decay in mammalian cells. In RNA turnover in eukaryotes: nucleases, pathways and anaylsis of mRNA decay (ed. Maquat LE, Kiledjian M), pp. 483-504. Elsevier, San Diego.

Parr CJC, Wada S, Kotake K, Kameda S, Matsuura S, Sakashita S, Park S, Sugiyama H, Kuang Y, Saito H. 2020. N ${ }^{1}$-methylpseudouridine substitution enhances the performance of synthetic mRNA switches in cells. Nucleic Acids Res 48: e35. doi:10.1093/nar/ gkaa070

Patil DP, Bakthavachalu B, Schoenberg DR. 2014. Poly(A) polymerasebased poly(A) length assay. In Polyadenylation: methods and protocols (ed. Rorbach J, Bobrowicz AJ), pp. 13-23. Humana, Totowa, NJ.
Pecoraro VL, Hermes JD, Cleland WW. 1984. Stability-constants of $\mathrm{Mg}^{2+}$ and $\mathrm{Cd}^{2+}$ complexes of adenine-nucleotides and thionucleotides and rate constants for formation and dissociation of MgATP and MgADP. Biochemistry 23: 5262-5271. doi:10.1021/ bi00317a026

Rose RE, Quinn R, Sayre JL, Fabris D. 2015. Profiling ribonucleotide modifications at full-transcriptome level: a step toward MS-based epitranscriptomics. RNA 21: 1361-1374. doi:10.1261/rna.049429 .114

Safaee N, Kozlov G, Noronha AM, Xie JW, Wilds CJ, Gehring K. 2012. Interdomain allostery promotes assembly of the poly(A) mRNA complex with PABP and elF4G. Mol Cell 48: 375-386. doi:10 .1016/j.molcel.2012.09.001

Sahin U, Kariko K, Tureci O. 2014. mRNA-based therapeutics: developing a new class of drugs. Nat Rev Drug Discov 13: 759-780. doi:10.1038/nrd4278

Schafer IB, Yamashita M, Schuller JM, Schussler S, Reichelt P, Strauss M, Conti E. 2019. Molecular basis for poly(A) RNP architecture and recognition by the Pan2-Pan3 deadenylase. Cell 177: 1619-1631. doi:10.1016/j.cell.2019.04.013

Sikorski PJ, Warminski M, Kubacka D, Ratajczak T, Nowis D, Kowalska J, Jemielity J. 2020. The identity and methylation status of the first transcribed nucleotide in eukaryotic mRNA $5^{\prime}$ cap modulates protein expression in living cells. Nucleic Acids Res 48: 1607-1626. doi:10.1093/nar/gkaa032

Stec WJ, Zon G. 1984. Synthesis, separation, and stereochemistry of diastereomeric oligodeoxyribonucleotides having a $5^{\prime}$-terminal internucleotide phosphorothioate linkage. Tetrahedron Lett 25: 5275-5278. doi:10.1016/S0040-4039(01)81582-3

Strenkowska M, Wanat P, Ziemniak M, Jemielity J, Kowalska J. 2012. Preparation of synthetically challenging nucleotides using cyanoethyl P-imidazolides and microwaves. Org Lett 14: 47824785. doi:10.1021/ol302071f

Strzelecka D, Chmielinski S, Bednarek S, Jemielity J, Kowalska J. 2017. Analysis of mononucleotides by tandem mass spectrometry: investigation of fragmentation pathways for phosphate- and ribose-modified nucleotide analogues. Sci Rep 7: 8931. doi:10 .1038/s41598-017-09416-6

Studzinska S, Rola R, Buszewski B. 2017. The impact of ion-pairing reagents on the selectivity and sensitivity in the analysis of modified oligonucleotides in serum samples by liquid chromatography coupled with tandem mass spectrometry. J Pharm Biomed Anal 138: 146-152. doi:10.1016/j.jpba.2017.02.014

Subtelny AO, Eichhorn SW, Chen GR, Sive H, Bartel DP. 2014. Poly(A)tail profiling reveals an embryonic switch in translational control. Nature 508: 66-71. doi:10.1038/nature13007

Svitkin YV, Cheng YM, Chakraborty T, Presnyak V, John M, Sonenberg N. 2017. $N^{1}$-methyl-pseudouridine in mRNA enhances translation through elF2 $\alpha$-dependent and independent mechanisms by increasing ribosome density. Nucleic Acids Res 45: 6023-6036. doi:10.1093/nar/gkx135

Topisirovic I, Svitkin YV, Sonenberg N, Shatkin AJ. 2011. Cap and capbinding proteins in the control of gene expression. Wiley Interdiscip Rev RNA 2: 277-298. doi:10.1002/wrna.52

Ueda T, Tohda H, Chikazumi N, Eckstein F, Watanabe K. 1991. Phosphorothioate-containing RNAs show messenger RNA activity in the prokaryotic translation systems in vitro. Nucleic Acids Res 19: 547-552. doi:10.1093/nar/19.3.547

Vicens Q, Kieft JS, Rissland OS. 2018. Revisiting the closed-loop model and the nature of mRNA 5'-3' communication. Mol Cell 72: 805812. doi:10.1016/j.molcel.2018.10.047

von Niessen AGO, Poleganov MA, Rechner C, Plaschke A, Kranz LM, Fesser S, Diken M, Lower M, Vallazza B, Beissert T, et al. 2019. Improving mRNA-based therapeutic gene delivery by 
expression-augmenting $3^{\prime}$ UTRs identified by cellular library screening. Mol Ther 27: 824-836. doi:10.1016/j.ymthe.2018.12 .011

Vortler LCS, Eckstein F. 2000. Phosphorothioate modification of RNA for stereochemical and interference analyses. RNA 317: 74-91.

Wahle E, Winkler GS. 2013. RNA decay machines: deadenylation by the Ccr4-Not and Pan2-Pan3 complexes. Biochim Biophys Acta 1829: 561-570. doi:10.1016/j.bbagrm.2013.01.003

Walczak S, Nowicka A, Kubacka D, Fac K, Wanat P, Mroczek S, Kowalska J, Jemielity J. 2017. A novel route for preparing 5' cap mimics and capped RNAs: phosphate-modified cap analogues obtained via click chemistry. Chem Sci 8: 260-267. doi:10.1039/ $\mathrm{C} 6 \mathrm{SC} 02437 \mathrm{H}$

Wan J, Shaw BR. 2005. Incorporation of ribonucleoside $5^{\prime}-(\alpha-P-b o r-$ ano)triphosphates into a 20-mer RNA by T7 RNA polymerase. Nucleosides Nucleotides Nucleic Acids 24: 943-946. doi:10 .1081/NCN-200059303

Warminski M, Sikorski PJ, Warminska Z, Lukaszewicz M, Kropiwnicka A, Zuberek J, Darzynkiewicz E, Kowalska J, Jemielity J. 2017. Amino-functionalized $5^{\prime}$ cap analogs as tools for site-specific sequence-independent labeling of mRNA. Bioconjug Chem 28: 1978-1992. doi:10.1021/acs.bioconjchem $.7 \mathrm{~b} 00291$

Weissman D, Pardi N, Muramatsu H, Karikó K. 2012. HPLC purification of in vitro transcribed long RNA. In Synthetic messenger RNA and cell metabolism modulation (ed. Rabinovich PM), pp. 43-54. Springer, New York

Westerich KJ, Chandrasekaran KS, Gross-Thebing T, Kueck N, Raz E, Rentmeister A. 2020. Bioorthogonal mRNA labeling at the poly(A) tail for imaging localization and dynamics in live zebrafish embryos. Chem Sci 11: 3089-3095. doi:10.1039/C9SC05981D

Wetzel C, Limbach PA. 2016. Mass spectrometry of modified RNAs: recent developments. Analyst 141: 16-23. doi:10.1039/C5AN 01797A
Wiederhold K, Passmore LA. 2010. Cytoplasmic deadenylation: regulation of mRNA fate. Biochem Soc Trans 38: 1531-1536. doi:10 .1042/BST0381531

Williams E, Sung S, Laskowski M. 1961. Action of venom phosphodiesterase on deoxyribonucleic acid. J Biol Chem 236: 1130-1134.

Wittmann T, Wahle E. 1997. Purification and characterization of fulllength mammalian poly(A) polymerase. Biochim Biophys Acta 1350: 293-305. doi:10.1016/S0167-4781(96)00164-9

Wojtczak BA, Sikorski PJ, Fac-Dabrowska K, Nowicka A, Warminski M, Kubacka D, Nowak E, Nowotny M, Kowalska J, Jemielity J. 2018. 5'-phosphorothiolate dinucleotide cap analogues: reagents for messenger RNA modification and potent small-molecular inhibitors of decapping enzymes. J Am Chem Soc 140: 5987-5999. doi:10.1021/jacs.8b02597

Wu Y, Tang Y, Dong X, Zheng YY, Haruehanroengra P, Mao S, Lin Q, Sheng J. 2020. RNA phosphorothioate modification in prokaryotes and eukaryotes. ACS Chem Biol 15: 1301-1305. doi:10 .1021/acschembio.0c00163

Wurdinger T, Badr C, Pike L, de Kleine R, Weissleder R, Breakefield XO, Tannous BA. 2008. A secreted luciferase for ex vivo monitoring of in vivo processes. Nat Methods 5: 171-173. doi:10.1038/nmeth.1177

Yamashita A, Chang TC, Yamashita Y, Zhu WM, Zhong ZP, Chen CYA, Shyu AB. 2005. Concerted action of poly(A) nucleases and decapping enzyme in mammalian mRNA turnover. Nat Struct Mol Biol 12: 1054-1063. doi:10.1038/nsmb1016

Yehudai-Resheff S, Schuster G. 2000. Characterization of the E. coli poly(A) polymerase: nucleotide specificity, RNA-binding affinities and RNA structure dependence. Nucleic Acids Res 28: 11391144. doi:10.1093/nar/28.5.1139

Ziemniak M, Strenkowska M, Kowalska J, Jemielity J. 2013. Potential therapeutic applications of RNA cap analogs. Future Med Chem 5: 1141-1172. doi:10.4155/fmc.13.96 

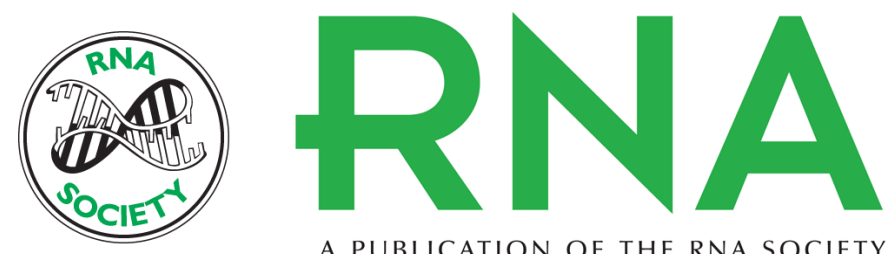

A PUBLICATION OF THE RNA SOCIETY

\section{Phosphodiester modifications in mRNA poly(A) tail prevent deadenylation without compromising protein expression}

Dominika Strzelecka, Miroslaw Smietanski, Pawel J. Sikorski, et al.

RNA 2020 26: 1815-1837 originally published online August 20, 2020

Access the most recent version at doi:10.1261/rna.077099.120

\section{Supplemental http://rnajournal.cshlp.org/content/suppl/2020/08/20/rna.077099.120.DC1 Material}

References This article cites 93 articles, 16 of which can be accessed free at: http://rnajournal.cshlp.org/content/26/12/1815.full.html\#ref-list-1

Open Access Freely available online through the RNA Open Access option.

Creative This article, published in $R N A$, is available under a Creative Commons License Commons (Attribution 4.0 International), as described at

License http://creativecommons.org/licenses/by/4.0/.

Email Alerting Receive free email alerts when new articles cite this article - sign up in the box at the Service top right corner of the article or click here.

To subscribe to $R N A$ go to:

http://rnajournal.cshlp.org/subscriptions 